\title{
INCIDENCIA DE LA LEGISLACION DESAMORTIZADORA SOBRE LOS MUNICIPIOS PERTENECIENTES AL PARTIDO JUDICIAL DE SALAMANCA (1855-1911)
}

348.737 (46. Salamanca)

$$
\text { por }
$$

\section{Angel Sánchez Blanco}

Profesor adjunto interino de Derecho administrativo

SUMARIO: I. INTRODUCCION.-II. ESTIMACION DE LA ENTIDAD ECONOMICA DE LOS BIENES DESAMORTIZADOS.-III. CONSI- " DERACION SOBRE LA CALIDAD DE LA TIERRA EN LOS BIENES DESAMORTIZADOS. - IV. ESTIMACION SOBRE LOS VALORES ALCANZADOS EN LA ADJUDICACION DE LAS PROPIEDADES MUNICIPALES SUBASTADAS. - V. OBSERVACIONES EN RELACION CON LOS ADJUDICATARIOS DE LAS PROPIEDADES SUBASTADAS. - VI. CORRELACION ENTRE BIENES DE PROPIOS Y BIENES COMUNALES EN LAS PROPIEDADES MUNICIPALES DESAMORTIZADAS.-VII. ESTIMACION ACTUAL DEL PATRIMONIO INMOBILIARIO DE LOS MUNICIPIOS PERTENECIENTES AL PARTIDO JUDICIAL DE SALAMANCA.-VIII. CONSIDERACIONES FINALES.-IX. APENDICES.

\section{INTRODUCCION}

La desamortización constituye uno de los grandes temas del siglo XIX, significa un revulsivo para la organización estatal, para las instituciones locales y para la Iglesia católica, e implica, a nivel económico, una oferta de tierras y bienes inmuebles sin precedentes en la historia económica y en torno a la cual se polarizan importantes inversiones, sin considerar que llega a provocar una auténtica mutación en la estructura de la propiedad territorial.

Las variables enunciadas concretan, de modo muy sucinto, la fenomenología que subyace en la desamortización; habría que aña- 
dir, desde la perspectiva bibliográfica, el dato de la escasez de estudios que aprecien valorativamente su significado y trascendencia (1).

En esta carencia de estudios encuentra justificación la tendencia a admitir puntos incuestionados sobre lo que la desamortización significó. En particular, sobre los bienes municipales desamortizados y sobre las consecuencias que la desamortización tuvo para los Municipios, se manifiestan, de modo habitual, juicios que toman, como premisa, el dato de que el fenómeno desamortizador significó el punto de inflexión entre una vida municipal aproblemática, articulada en torno a los bienes de propiedad municipal, y una situación que gravó a las entidades municipales con serios problemas, como efecto inducido de la pérdida de sus bienes, a consecuencia de la aplicación de la normativa desamortizadora (2).

(1) En la bibliografía sobre la desamortización destacan los nombres de Simón Segura y Tomás VALIENTE, que han contribuido a clarificar un tema cuyo olvido no se justifica con facilidad cuando se consideran las consecuencias que - la desamortización ha tenido para la reciente historia de España. Ambos autores han iniciado prácticamente los estudios sobre la desamortización $\mathrm{y}$, al margen de sus trabajos introductorios, que consideran globalmente la desamortización (vid. Simón SEGURA: "La desamortización de 1855", Economía Financiera, núms. 19-20, 1968, y La desamortización española del siglo XIX, Instituto de Estudios Fiscales, Madrid, 1973. Vid. Tomás VALIENTE: El marco politico de la desamortización en España, Barcelona, 1971), han iniciado líneas monográficas de investigación de notable interés para la estimación valorativa del fenómeno desamortizador (vid. Simón Segura: Contribución al estudio de la desamortización en España. La desamortización de Mendizábal en la Provincia de Gerona, Madrid, 1969; Contribución al estudio de la desamortización en España. La desamortización de Mendizábal en la Provincia de Madrid, Madrid, 1969; "La desamortización de 1855 en la Provincia de Ciudad Real», Revista de Hacienda Pública, núm. 27, 1974. Vid. Tomás VALIENTE: «Bienes exentos y bienes exceptuados de desamortización (análisis de la jurisprudencia del Consejo de Estado y del Tribunal Supremo entre 1873 y 1880)", en Actas del III Simposium de Historia de la Administración, IEA, Madrid, 1974, págs. 61-93, y el trabajo de Borrego Bellido, Casero Lambas y GuTIÉRREZ SARMIENTO, dirigido por Tomás Valiente y publicado igualmente en las Actas del III Simposium de Historia de la Administración, págs. 35-60, «Bienes exentos y bienes exceptuados de la desamortización. Análisis de la jurisprudencia entre 1866-1877".

(2) Significativo para apreciar las opiniones políticas y doctrinales operantes en esta línea es el trabajo de don Cirilo Martfo-Retortillo González: El Mu. nicipio rural. Notas sobre su personalidad, su economia y su hacienda, Barcelona, 1950. Vid. de modo especial el capítulo II, dedicado al análisis de «El patrimonio de los Municipios rurales y sus productos», págs. 25-41. La posición del autor se identifica, en dureza, con las posiciones doctrinales que le precedieron y que el autor refleja en su trabajo; adecuada muestra se puede encontrar en las siguientes palabras: «La desamortización... degeneró en un feroz despojo que esquilmó a los Municipios rurales, arrebatándoles la mayor y mejor parte de su patrimonio inmobiliario para pasarlo a unos titulares privados mediante la entrega de unas pocas pesetas en unas láminas intransferibles que escasamente habian de rentarles lo bastante para cubrir los gastos que había de originar la cobranza de esos intereses» (vid. op. cit., pág. 30). En relación con el mismo tema, 
Influido por estos planteamientos inicié este estudio, en el que he tratado de evaluar los bienes desamortizados a los Municipios del Partido judicial de Salamanca; sin embargo, y en contra de lo que consideraba como un presupuesto a ratificar, en base a los datos aportados por los Boletines de Venta de Bienes Nacionales, he llegado a la conclusión opuesta: la entidad de los bienes municipales en el momento de comenzar la desamortización era ya muy escasa en la mayor parte de los Municipios del Partido judicial estudiado. A medida que la recopilación de datos avanzaba, he ido confirmando la imposibilidad de apreciar bienes con la suficiente entidad como para llegar a la conclusión de que en torno a ellos pudiera articularse la vida municipal. La contraposición entre las tradicionales posiciones doctrinales sobre la incidencia de la desamortización en los bienes municipales y las conclusiones obtenidas sobre los Municipios del Partido judicial de Salamanca son sensibles, y pudieran pasar desapercibidas si el Partido judicial careciera. de cualificación como muestra, pero, por el contrario, concurren en él circunstancias cualificadoras, concretadas en que implica un número relativamente elevado de Municipios (sesenta y tres), y unas circunstancias económicas y geográficas que confieren una fuerte heterogeneidad a los Municipios que integra.

En el Municipio de Salamanca se concreta el punto de transición entre la economía pecuaria de los pueblos situados al oeste de la ciudad, sobre los que aún se deja sentir la influencia del clima atlántico, y la economía agraria de los pueblos situados al este, afectados por el clima continental extremado de la meseta; implica también la transición entre las estribaciones de la sierra de Francia, en la que se sitúan Municipios, como Las Veguillas, San Pedro

GARCfA DE ENTERRfA estima que «la desamortización supuso la ruina de la hacienda de muchos entes locales", y, después de significar que la desamortización implicó la sustitución de los ingresos procedentes de los bienes patrimoniales por la aplicación a los Municipios del sistema de hacienda tributaria, hace notar que la vigencia de este sistema ha sido «fuente continua de dificultades e inconvenientes hasta tal punto que la situación actual de los Municipios es de crisis agudísima, tanto que prácticamente puede decirse que hoy ya no existen los Ayuntamientos" (vid. GARcfa DE ENTERRfA: Apuntes de Derecho administrativo. Curso 1971-1972, tomo I, pág. 203, Madrid, 1971). No obstante, y en relación con la posición de GARcfa DE ENTERRfa, es preciso señalar una cierta relativización del signficado de la desamortización como factor trascendental en el deterioro de la infraestructura del Municipio. En este sentido tiene interés el análisis que realiza GARCfA DE ENTERRfa sobre el proceso de deterioro de la entidad de los bienes municipales y los cambios registrados en relación con la titularidad jurídica de estos bienes en los años precedentes a 1855 en su estudio sobre «Las formas comunitarias de propiedad forestal y su posible proyección futuras, Anuario de Derecho Civil, 1976, págs. 283-289. 
de Rozados y Cilleros el Hondo, y núcleos de población de la meseta tan distintos a los mencionados como los armuñeses de Aldeanueva de Figueroa, Topas o Palencia de Negrilla. A nivel hídrico se registran transiciones tan notorias como la constatable entre pueblos situados en la vega del Tormes (Florida de Liébana, o Santa Marta, Pino de Tormes) y núcleos municipales, como Arapiles, Palencia de Negrilla o Castellanos de Villiquera, con unas condiciones hidrológicas totalmente diversas. También cualifica al modelo el contraste entre Municipios en las estribaciones de la sierra, afectados por un sensible aislamiento que sólo en la actualidad comienza a superarse, con Municipios situados en el ámbito de influencia de la capital provincial. Los Municipios de Las Veguillas y Tejares ilustran este último aspecto.

Desde la perspectiva de concreción de fuentes utilizadas y de la metodología seguida, he de considerar que, como base documental, se ha utilizado la colección del Boletín de Ventas de Bienes Nacionales de la Provincia de Salamanca, perteneciente al Archivo Histórico Provincial de la misma Provincia, complementada por informaciones directas realizadas ante los Secretarios de los respectivos Ayuntamientos.

El período estudiado ha comprendido los años 1855-1911, que implica la totalidad del período desamortizador con incidencia sobre los bienes municipales.

La base sobre la que se fundamenta el estudio se ha concretado en la sistematización, por Municipios, de los datos relativos a cada una de las subastas anunciadas en el Boletín de Venta de Bienes Nacionales $(B V B N)$. En este sentido se han considerado las características de las propiedades subastadas, con especial atención a sus extensiones superficiales y calidad de la tierra, calificación y situación jurídica de los bienes, tasación de cada lote de bienes y tipo de salida a subasta y, finalmente, determinación del adjudicatario y cantidad de la adjudicación.

Preciso es que hagamos la observación de que algunos casos, por carencia de Boletín o por defectos de encuadernación, unido a la prolijidad de datos, no ha sido posible concretar, en relación con algunos bienes, todos los puntos de referencia de que hemos hecho mención. A esta circunstancia no es ajena la progresiva simplificación de los datos publicados en los $B V B N$, que hacia 1899 comienzan a desconsiderar la distinción de bienes comunales y bienes de propios y pierden, de modo progresivo, la minuciosidad y perfec- 
ción de los primeros Boletines de Ventas. Con punto de apoyo en los datos mencionados, he elaborado la primera parte del trabajo, que se ha centrado en la estimación económica de los bienes desamortizados, apreciando en su aspecto cuantitativo y cualitativo estos bienes. Como técnicas instrumentales han sido estudiadas sus superficies, la relación de estas superficies con la superficie total del respectivo término municipal, la composición de los lotes subastados y particularidades geológicas o geográficas que concurren en los bienes. El punto segundo del trabajo se centra en la apreciación de la calidad de la tierra en las superficies subastadas, con base en los datos que, de modo casuístico, aportan los Boletines, para analizar a continuación, y como punto tercero, los valores alcanzados en la adjudicación de las propiedades municipales subastadas; para ello utilizo en la sistematización de los datos relativos a las superficies de cada lote subastado, base de salida o subasta, cantidad en que fue adjudicado, porcentaje de variación entre la base de salida y la cantidad de adjudicación. Estos datos obran en el apéndice número $1 \mathrm{y}$ estimamos que son muy significativos como instrumento valorativo del fenómeno desamortizador en los $\mathrm{Mu}$ nicipios estudiados.

En el punto $4 .^{\circ}$ centro la atención en las particularidades que concurren en los adjudicatarios de los bienes en relación con el término municipal en que adquieren bienes desamortizados y el término municipal de su residencia personal. La correlación de estos datos, que constituyen el apéndice número 2 , estimo que son de importancia para apreciar la dinámica económica que orientó la desamortización en los términos municipales objeto de nuestro estudio.

Como punto $5 .^{\circ}$ considero la relación existente entre los bienes de propios y los bienes comunales, con objeto de apreciar la composición y funcionalidad de los bienes desamortizados. La base documental relativa a este punto constituye el apéndice número 3, gravado, como ya mencioné, por la indistinción de los Boletines, a partir de 1889, entre bienes comunales y bienes de propios.

En el punto $6 .^{\circ}$ del estudio realizo una estimación de los patrimonios inmobiliarios municipales en la actualidad; con ello trato de apreciar si los Municipios afectados por la desamortización hicieron uso de la excepción prevista por la legislación desamortizadora para eludir la venta de determinados bienes comunales y, como consecuencia, corroborar o corregir la identificación entre patri- 
monio municipal y bienes desamortizados. La base documental utilizada para la estimación actual de los patrimonios municipales constituye el apéndice número 4.

Unas apreciaciones finales cierran el estudio.

\section{ESTIMACION DE LA ENTIDAD ECONOMICA DE LOS BIENES DESAMORTIZADOS}

La estimación efectuada sobre los bienes municipales vendidos en pública subasta en el período 1855-1911, en expresa referencia a su superficie, nos permite llegar a la conclusión de que los bienes municipales de los Ayuntamientos pertenecientes al Partido judicial de Salamanca carecen de entidad superficial y, en consecuencia, de entidad económica.

De los 49 Municipios afectados por la legislación desamortizadora, incluida la capital provincial, el número de Municipios que parecen estar prácticamente desdotados de bienes municipales se eleva a 22. A continuación relacionamos los Municipios que permiten afirmar que carecen de propiedades municipales territoriales. Junto al nombre del Municipio expresamos la superficie de los bienes subastados y el porcentaje que la superficie subastada significa en relación con la superficie del término municipal.

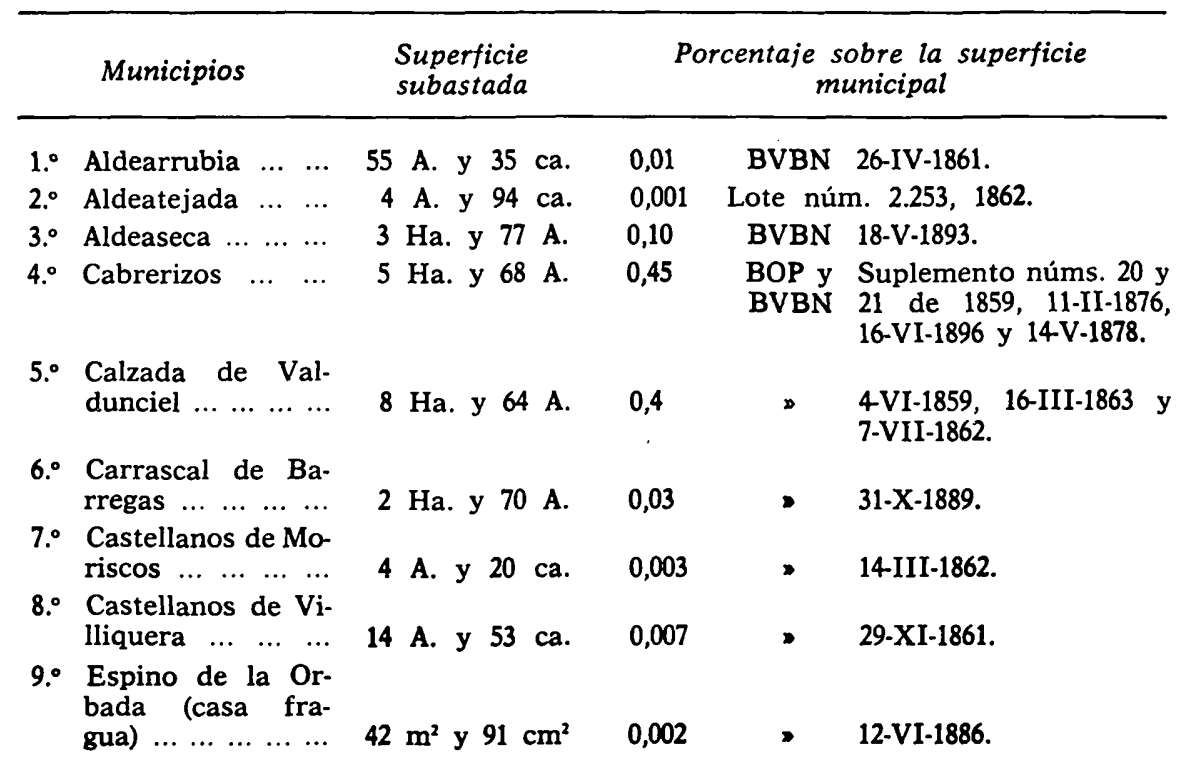




\begin{tabular}{|c|c|c|c|c|c|}
\hline \multirow{2}{*}{$\frac{}{10 .}$} & \multirow{2}{*}{$\begin{array}{c}\text { Municipios } \\
\text { Forfoleda ... ... ... }\end{array}$} & $\begin{array}{l}\text { Superficie } \\
\text { subastada }\end{array}$ & \multicolumn{3}{|c|}{$\begin{array}{l}\text { Porcentaje sobre la superficie } \\
\text { municipal }\end{array}$} \\
\hline & & 7 A. y $26 \mathrm{ca}$. & 0,02 & BVBN & $27-I-1862$. \\
\hline $110^{\circ}$ & Gomecello ... ... ... & 7: Ha. y 75 A. & 0,3 & - & $15-X-1862$ y $11-V I I-1873$ \\
\hline $12 .^{\circ}$ & La Velles $\ldots \ldots \ldots$ & 5 Ha. y 42 A. & 0,2 & 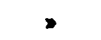 & 22-VII-1897. \\
\hline $13 .^{\circ}$ & Miranda de Azán. & 5 Ha. y 3 A. & 0,02 & > & 4IX-1862. \\
\hline $14 .^{\circ}$ & Moriscos $\ldots \ldots \ldots$ & $4 \mathrm{Ha}$ y $91 \mathrm{~A}$. & 0,3 & » & $30-I V-1859$ y 14 III-1862. \\
\hline $150^{\circ}$ & $\begin{array}{l}\text { Monterrubio de la } \\
\text { Armuña } \quad \ldots \quad \ldots l\end{array}$ & 4 A. y 13 ca. & 0,03 & $\checkmark$ & 16-VI-1863. \\
\hline $160^{\circ}$ & $\begin{array}{lllll}\text { Palencia } & \text { de } & \mathrm{Ne} \\
\text { grilla } & \ldots & \ldots & \ldots & \ldots\end{array}$ & $14 \mathrm{Ha}$ y $21 \mathrm{~A}$. & 0,8 & 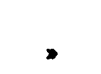 & 26-VII-1877 y 4-IV-1894 \\
\hline $170^{\circ}$ & Pedrosillo el Ralo. & 1 Ha. y 19 A. & 0,1 & s & 4IV-1894. \\
\hline $18 .^{\circ}$ & Topas $\ldots \ldots \ldots$ & 10 A. y $96 \mathrm{ca}$. & 0,0009 & - & 14-III-1862. \\
\hline $19 .^{\circ}$ & Valverdón ... ...... & 48 A. y 74 ca. & 0,02 & 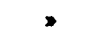 & $17-V-1861$ \\
\hline $200^{\circ}$ & Villamayor $\ldots \ldots$ & 65 A. y 3,5 ca. & 0,1 & $\triangleright$ & 23-VII-1863 y 22-VII-1872. \\
\hline $21 .^{\circ}$ & 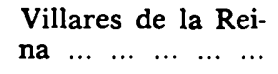 & $190 \mathrm{~m}^{2}$ (urbana) & 0,007 & - & $18-V-1893$ \\
\hline $22 .^{\circ}$ & $\begin{array}{llll}\text { Villaverde } & \text { de } & \text { la } \\
\text { Guareña } & \ldots & \ldots & \ldots\end{array}$ & $\begin{array}{l}1 \mathrm{Ha}, 90 \text { A. } y \\
50 \mathrm{~m}^{2} \text { de una } \\
\text { fragua }\end{array}$ & 0,11 & $\triangleright$ & $\begin{array}{l}\text { 14-III-1862, 4-IV-1894 у } \\
\text { 17-IV-1897. }\end{array}$ \\
\hline
\end{tabular}

En consecuencia, y conforme a los datos reflejados, se puede llegar a la conclusión de que el 46 por 100 de los Municipios del Partido judicial de Salamanca que fueron afectados por la legislación desamortizadora carecen de propiedades municipales de carácter territorial.

Entre los Municipios que tienen un porcentaje de bienes municipales situados entre el 1 y el 3,5 por 100 es posible citar:

\begin{tabular}{|c|c|c|c|}
\hline & Municipios & Superficie subastada & $\begin{array}{c}\text { Porcentaje sobre } \\
\text { la superficie } \\
\text { municipal }\end{array}$ \\
\hline $1 .^{\circ}$ & $\begin{array}{lllllllllll}\text { Aldealengua } & \ldots & \ldots & \ldots & \ldots & \ldots & \ldots & \ldots & \ldots & \ldots\end{array}$ & 18 Ha. y 30 A. & 3,25 \\
\hline $2 .^{\circ}$ & $\begin{array}{cccccccccc}\text { Arapiles } & \ldots & \ldots & \ldots & \ldots & \ldots & \ldots & \ldots & \ldots & \ldots\end{array}$ & $21 \mathrm{Ha}$ y 72 A. & 1,03 \\
\hline $3 .^{\circ}$ & Calvarrasa de Arriba $\ldots \ldots \ldots \ldots \ldots$ & $41 \mathrm{Ha}$ y $11 \mathrm{~A}$. & 1,8 \\
\hline $4 .^{\circ}$ & Carbajosa de la Sagrada $\ldots \ldots \ldots \ldots$ & $34 \mathrm{Ha}$ y $46 \mathrm{~A}$. & 2,5 \\
\hline $5 .^{\circ}$ & Cilleros el Hondo $\ldots \ldots \ldots \ldots \ldots$ & 74 Ha. y 13 A. & 3,5 \\
\hline $6^{\circ}$ & 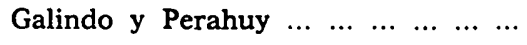 & 115 Ha. y 57 A. & 2 \\
\hline $7 .^{\circ}$ & $\begin{array}{llllllllll}\text { Las } & \text { Torres } & \ldots & \ldots & \ldots & \ldots & \ldots & \ldots & \ldots & \ldots\end{array}$ & $14 \mathrm{Ha}$ y 94 ca. & 1,5 \\
\hline 8. & Pajares de la Laguna $\ldots \ldots \ldots \ldots \ldots$ & $37 \mathrm{Ha}$ y $53 \mathrm{~A}$. & 3 \\
\hline $9 .^{\circ}$ & $\begin{array}{lllllllll}\text { Parada de } \text { Arriba } & \ldots & \ldots & \ldots & \ldots & \ldots & \ldots\end{array}$ & 65 Ha. y 29 A. & 3 \\
\hline $10 .^{\circ}$ & San Pedro de Rozados $\ldots \ldots \ldots \ldots$ & $390 \mathrm{Ha}$ y 51 A. & 3 \\
\hline $110^{\circ}$ & Santa Marta de Tormes $\ldots \ldots \ldots \ldots$ & $18 \mathrm{Ha}$ y $14 \mathrm{~A}$. & 1,8 \\
\hline
\end{tabular}


No obstante, el incremento porcentual de los bienes municipales en los 11 Municipios que acabamos de relacionar es notablemente relativizado por la circunstancia de que la consideración pormenorizada de las superficies territoriales que poseen se caracteriza por una notable parcelación en sus propiedades, circunstancia que aminora de modo considerable el interés económico de los bienes desamortizados.

Es muy significativo constatar cómo el Municipio de Aldealengua, cuya relación porcentual, considerando la suma conjunta de sus propiedades, es la más elevada, descompone sus $18 \mathrm{Ha}$. en los siguientes lotes: seis prados, cuya extensión mayor alcanza $1 \mathrm{Ha}$. y 59 A.; siete tierras, cuya extensión mayor se concreta en $2 \mathrm{Ha}$., dos pedazos de valle, el mayor de los cuales es de $2 \mathrm{Ha}$., y un pedazo de terreno de 2 Ha. y 3 A. (3).

En el caso del Municipio de Arapiles, la fragmentación de la propiedad municipal no es menor. Sus $21 \mathrm{Ha}$ y $72 \mathrm{~A}$. se desglosan en 20 tierras de labor, cuya suma de superficies alcanza $11 \mathrm{Ha}$. y 26 A.; las elevaciones del "Arapil Grande» y "Arapil Chico", con 9 y $2 \mathrm{Ha}$. de superficie, respectivamente, y cuyo valor histórico es, sin duda, mayor que el económico; una reducida alameda de $5 \mathrm{~A}$. y 3 ca. de extensión, y un prado poseído "a medias», y así denominado, con el Ayuntamiento de Mozárbez, cuya extensión se concreta en 1 Ha. y 39 A. (4).

La fragmentación de la propiedad municipal del Municipio de Calvarrasa de Arriba es también notoria; sus $41 \mathrm{Ha}$. de propiedades territoriales se dividen entre 24 tierras, las mayores de las cuales alcanzan las 8 y $2 \mathrm{Ha}$., reduciéndose la mayoría de las tierras restantes a superficies menores de $1 \mathrm{Ha}$. (5).

Carbajosa de la Sagrada no se margina de la tendencia señalada. La composición de $34 \mathrm{Ha}$. de propiedades se parcelan en 13 tierras, que suman $8 \mathrm{Ha}$. y $80 \mathrm{~A}$; cinco prados, cuya superficie está al nivel de las $4 \mathrm{Ha}$. y $50 \mathrm{~A}$.; una alameda, de $5 \mathrm{~A}$. y $3 \mathrm{ca}$., y dos propiedades, con una extensión relativamente apreciable, al menos en relación con la superficie del resto de las propiedades municipales, 6 y 19 hectáreas, denominadas con el significativo toponímico de "cuestas grandes» y "cuestas chicas», que, en referencia a la calidad de la tierra, están consideradas por los $B V B N$ como de «tercera y la

(3) $B V B N, 30-I V-1859$ y 30-I-1864.

(4) $B V B N, 28-V-1859,24 X-1862$ y 17-IX-1873.

(5) $B V B N, 4-1894$. 
mayor parte inútil», calificándose, de modo expreso, el terreno de "cuesta chica» como "escabroso» (6).

La municipalidad de Las Torres reparte sus $14 \mathrm{Ha}$. y $94 \mathrm{ca}$. entre 26 trozos de terreno, cuyas mayores superficies individuales se concretan en 6 y $3 \mathrm{Ha}$., no alcanzando el resto de los terrenos la hectárea de superficie (7).

En Pajares de la Laguna son 18 los «trozos de terreno" que componen el lote de bienes municipales, cuya superficie conjunta suma las $37 \mathrm{Ha}$., siendo el equivalente de la superficie del trozo mayor a $20 \mathrm{Ha}$., pero que, a efectos de valorar su entidad económica, nos obliga reseñar que figura bajo el sospechoso toponímico de "calvas» (8).

Parada de Arriba, con menor superficie de bienes territoriales que Pajares de la Laguna, $14 \mathrm{Ha}$. y $21 \mathrm{~A}$., reparte esta menor superficie entre cuatro trozos de terreno que alcanzan las $2 \mathrm{Ha}$. y 35 ca., cinco trozos cuya superficie conjunta es de $2 \mathrm{Ha}$. y $91 \mathrm{ca}$., diez trozos con superficie conjunta de $8 \mathrm{Ha}$. y $22 \mathrm{~A}$. y dos tierras que suman en superficie 72 A. y 76 ca. (9).

El Municipio de Santa Marta de Tormes permite, como en los precedentes casos, apreciar un logrado ejemplo de parcelación de la propiedad municipal. Sus $18 \mathrm{Ha}$ y $14 \mathrm{~A}$. de propiedades territoriales se dividen en 23 pedazos de tierra, de los cuales sólo cuatro superan la hectárea de extensión superficial. Una alameda de 2 A. y 75 ca., con "negrillos de escaso fomento», completa los bienes municipales de Santa Marta de Tormes (10).

La consideración conjunta de los 23 Municipios en los que la superficie de bienes municipales no alcanzaba el 1 por 100 de la superficie del término municipal respectivo, y el complemento de los ocho Municipios en los que concurre la circunstancia de que superan, en algunos casos, el 3 por 100 de la superficie municipal, pero cuya fragmentación de la propiedad descalifica la entidad económica de los bienes municipales, nos permite hacer observar que más de 31 de los Municipios del Partido judicial de Salamanca, del total de 49 afectados por la desamortización, carecían, en 1855, de bienes municipales territoriales con cierta entidad económica, circunstancia que implica que un porcentaje que se eleva al 62 por 100

(6) $B V B N$, 29-XI-1861, 10X-1878, 24III-1891 у 4-I-1894.

(7) $B V B N$, 11-XI-1876.

(8) $B V B N$, 8-VIII-1873.

(9) $B V B N$, 9-XII-1861 y 3-I-1893.

(10) $B V B N, 22-X I I-1860$ y 2-XI-1892. 
de los Muncipios tenían en 1855 un patrimonio municipal inmobiliario irrelevante.

De los Municipios hasta ahora mencionados únicamente se marginan de la ausencia de entidad de sus bienes municipales el Ayuntamiento de Galindo y Perahuy (11), con una superficie que, si bien sólo equivale al 2 por 100 de la superficie municipal, presenta la extensión, relativamente apreciable, de $115 \mathrm{Ha}$ y 57 A., y el Ayuntamiento de San Pedro de Rozados (12), que, con el 3 por 100 de la superficie territorial del Municipio en bienes municipales, alcanza una superficie en sus propiedades de $390 \mathrm{Ha}$. y $51 \mathrm{~A}$. Tampoco puede ser olvidado el caso del Ayuntamiento de Cilleros el Hondo (13), que presenta la peculiaridad de alcanzar la proporción del 3,5 por 100 de sus bienes municipales en relación con la total superficie territorial del Municipio. No obstante, presenta la misma tónica de parcelación de propiedad territorial que los Municipios precedentes. De sus $74 \mathrm{Ha}$. de propiedades, 12 están repartidas entre 18 trozos de terreno y dos exiguas alamedas. Las $62 \mathrm{Ha}$. restantes pertenecen a un monte de propios, en relación con el cual sólo existe reconocido derecho al vuelo sobre 6.000 encinas, concurriendo la circunstancia de que su aprovechamiento está sin arrendar, situación infrecuente si se considera la descripción que los $B V B N$ hacen de los bienes de propios. La subasta de este encinar es anulada por acuerdo de la Junta Superior, de fecha 28 de diciembre de 1861 , sin que hayamos encontrado constancia de posterior salida a subasta. No obstante, como reflejamos en el apéndice número 4, el Ayuntamiento de Cilleros el Hondo carece de este aprovechamiento y de cualquier otro tipo de bienes comunales o de propios.

Intencionalmente hemos reservado la consideración de los $\mathrm{Mu}$ nicipios de Galindo y Perahuy y San Pedro de Rozados para el final de este apartado de nuestro trabajo, debido a que ambos Municipios se marginan de la tónica de irrelevancia de los bienes municipales que parece caracterizar al resto de los Municipios.

En el caso de San Pedro de Rozados, las características que concurren en sus bienes no se pueden considerar radicalmente ajenas a la notable parcelación de las propiedades municipales como pe-

(11) $B V B N$, 2-VI-1871, 8-VII-1873 y 13-II-1884.

(12) $B O P$, suplemento núm. 32, 1859, y $B V B N$, 21-I-1860, 21-I-1864, 7-VII-1872, 5-II-1875, 27-II-1901, 1-X-1901 y 16-II-1905.

(13) BOP, suplemento núm. 21, 1859. 
culiaridad que define los bienes municipales del Partido judicial de Salamanca. San Pedro de Rozados tenía divididas $295 \mathrm{Ha}$. de sus bienes territoriales en 57 pedazos de tierra, circunstancia que relativiza la entidad cualitativa de los bienes poseídos. No obstante, presenta la particularidad de poseer una dehesa boyal de $83 \mathrm{Ha}$. y $71 \mathrm{~A}$. y un monte boyal de $82 \mathrm{Ha}$. y $36 \mathrm{~A}$., si bien la notable exten. sión del término municipal, $10.326 \mathrm{Ha}$., no permite considerar significativo, en exceso, el dato de la posesión por el Ayuntamiento de dos extensiones superficiales de alrededor de $80 \mathrm{Ha}$. cada una.

Galindo y Perahuy tiene la particularidad de presentar, en contraste con los casos precedentes, una estructura de la propiedad municipal de la que está ausente la fragmentación que minora el significado económico de los bienes territoriales de las municipalidades hasta ahora objeto de nuestra atención. El Ayuntamiento de Galindo y Perahuy poseía tres terrenos de $36 \mathrm{Ha}$ y $70 \mathrm{~A}$., $34 \mathrm{Ha}$. y $78 \mathrm{~A}$ y $40 \mathrm{Ha}$. y $47 \mathrm{~A}$. Sin embargo, es matizable la posible entidad atribuida a estos bienes si se considera que en los lotes números 829-838 y 839 concurre la circunstancia de injustificadas suspensiones de subasta y celebración de segunda subasta en la venta conjunta de los terrenos de $34 \mathrm{Ha}$ : y $78 \mathrm{~A}$. y $40 \mathrm{Ha}$. y $47 \mathrm{~A}$., situación insólita si se tiene en consideración que una de las características peculiares que se observan en la subasta de los bienes municipales del Partido judicial de Salamanca es, precisamente, la adjudicación con altos tipos en relación con el tipo inical de subasta y la inexistencia de segundas subastas, salvo en los reducidos casos de quiebra que se dieron en el período estudiado.

Las circunstancia señaladas en los Municipios de San Pedro de Rozados y Galindo y Perahuy contribuyen a relativizar la entidad cuantitativa de las propiedades territoriales de ambos Municipios desde apreciaciones cualitativas de carácter negativo.

Como producto de la consideración más detallada de las circunstancias que concurren en los tres últimos Municipios considerados podríamos llegar a la conclusión de que el porcentaje de Municipios del Partido judicial, cuyos bienes municipales territoriales carecen de significado económico cualificado, supera el 62 por 100 , para situarse en el 68 por 10033 de los 49 Municipios del Partido, en los que la normativa desamortizadora encuentra aplicación.

A continuación estudiaremos las características que concurren en los Municipios en los que las propiedades territoriales munici- 
pales parecen superar la precaria situación de los 31 Muncipios que han sido objeto de nuestra inicial atención.

En los 15 Municipios restantes, incluido el de la capital de la Provincia, la situación es muy desigual en la entidad de los bienes. Porcentualmente oscila entre un 5 por 100 en relación con la total superficie municipal en el Municipio de Pelabravo, y un 27 por 100 en Torresmenudas. No obstante, y al margen de estimaciones porcentuales, las peculiaridades que concurren en las propiedades municipales crean situaciones muy diversas en la conformación de los bienes de cada una de las municipalidades. Pasamos a considerar la composición de la propiedad territorial en cada uno de los $\mathrm{Mu}$ nicipios.

En Aldeanueva de Figueroa las propiedades municipales tienen notable entidad. Poseía tres extensiones superficiales, consideradas como de "propios", con superficies medias notables, al menos teniendo presente la baja entidad de las extensiones medias existentes en los Municipios hasta ahora considerados. Las superficies medias de 57, 87 y $140 \mathrm{Ha}$. son, como hemos tenido ocasión de apreciar, inusuales. Aparte de las superficies mencionadas y calificadas como "comunales», el Municipio de Aldeanueva de Figueroa poseía otras dos superficies de 38 y $62 \mathrm{Ha}$., y como terrenos "propios" poseía también cuatro superficies de $8,15,17$ y $18 \mathrm{Ha}$. Como puede observarse, el conjunto de propiedades del Municipio de Aldeanueva de Figueroa forma un patrimonio estimable en su entidad. La suma de superficies desamortizadas al Ayuntamiento de Aldeanueva de Figueroa permitía alcanzar el 8,10 por 100 de la total superficie territorial del Municipio (14).

La situación es muy distinta en el Municipio de Arcediano, cuyas propiedades, aunque alcanzan el 10 por 100 de la superficie municipal por un total de $113 \mathrm{Ha}$., están fragmentadas en cuatro solares, 114 tierras y 13 fincas, con unas superficies medias de muy reducida extensión (15).

Barbadillo presenta una problemática muy similar a la de Aldeanueva de Figueroa. Las extensiones medias de sus seis propiedades comunales, entre 24 y $63 \mathrm{Ha}$., constituyen un conjunto de cierta entidad física y económica (16).

(14) $B V B N, 29-V I I I-1863$ y 7-XI-1871.

(15) $B V B N$, 6-VII-1859, 16-III-1872 y 21-VII-1906.

(16) $B V B N, 29 . V I I-1860,24-V I I I-1870$ y 17-VI-1887. 
Calvarrasa de Abajo se identifica también en la estructura de su propiedad con los Municipios de Aldeanueva y Barbadillo, cuyas extensiones medias en tres propiedades alcanzan las 30,38 y 100 hectáreas, implicando el conjunto de las propiedades municipales el 8,6 por 100 de la superficie municipal (17). Carrascal del Obispo también contaba con un patrimonio, conjuntamente alcanzaba las $500 \mathrm{Ha}$., y que, si bien se fragmentaba en algunas pequeñas parcelas, contaba con cuatro unidades comunales de 93, 101, 106 y 158 hectáreas, que, sin duda, cualifican el estimable porcentaje del 12 por 100 alcanzado por el Municipio de Carrascal del Obispo en la extensión de sus propiedades municipales en relación con la total superficie del término (18).

La entidad de los bienes municipales de Aldeanueva, Barbadillo, Calvarrasa de Abajo y Carrascal del Obispo quiebra en el caso de Doñinos de Salamanca (19), que, con una extensión de $146 \mathrm{Ha}$., que significan un 6 por 100 de la total superficie del término municipal, se parcela en 16 unidades superficiales que oscilan entre las $8 \mathrm{~A}$ y $16 \mathrm{Ha}$. La mayor extensión superficial, al margen de las 16 unidades mencionadas, se concreta en una superficie dedicada a pasto de $32 \mathrm{Ha}$. Florida de Liébana, en contraposición con Doñinos de Salamanca, nos vuelve a permitir apreciar unas propiedades municipales que contabilizan un conjunto de hectáreas relativamente elevado y que, al mismo tiempo, no presenta el problema de la fragmentación en unidades de pequeña superficie que minoran la entidad económica de las propiedades. El Municipio de Florida de Liébana estructura sus propiedades territoriales en tres superficies de 16,26 y $100 \mathrm{Ha}$. El resto lo constituyen tres parcelas situadas superficialmente en torno a una hectárea (20).

Mozárbez constituye el ejemplo extremo de un Municipio con una apreciable extensión territorial en relación con la superficie total de su término: $287 \mathrm{Ha}$., que representan el 11 por $100 \mathrm{de} \mathrm{la}$ superficie municipal, pero cuya fragmentación en una alameda, cinco prados y 216 tierras desvirtúa la posible entidad operativa de los bienes (21).

Parada de Rubiales no está lejana de la problemática de Mozárbez. Las $346 \mathrm{Ha}$. de bienes municipales, que representan un 11

(17) $B V B N$, 29-IV-1859, 8-VIII-1873 y 13-XII-1873.

(18) $B V B N, 22-V I-1887$.

(19) $B V B N, 29-\mathrm{XI}-1861$.

(20) $B V B N, 29-V I I-1860$ y 18-VIII-1860.

(21) $B V B N$, 21-VII-1859, 12-VIII-1859 y 24X-1862. 
por 100 de la superficie del Municipio, se fragmentan en 32 unidades superficiales, las mayores de las cuales corresponden a 28 , 44 y $56 \mathrm{Ha}$., en las que concurre la circunstancia de ser bienes baldíos (22).

El Municipio de Pelabravo, con sólo un 5 por 100 de propiedades municipales en relación con su superficie territorial y con únicamente $124 \mathrm{Ha}$. de superficie, presenta una composición de sus bienes más equilibrada que los casos precedentes de Mozárbez y $\mathrm{Pa}$ rada de Rubiales. Las $124 \mathrm{Ha}$. se distribuyen básicamente en tres unidades de 14, 36 y $72 \mathrm{Ha}$., complementadas con una pequeña alameda de 3 A. y 13 ca. (23).

En el caso de San Cristóbal de la Cuesta, si bien el porcentaje de la superficie de bienes municipales estimado se sitúa al nivel del 5 por 100 , esta cifra carece de cualificación si se considera la poca extensión del término municipal de $995 \mathrm{Ha}$. San Cristóbal de la Cuesta tampoco se sitúa al margen del inconveniente de la fragmentación de sus propiedades, ya que si bien posee un prado de $34 \mathrm{Ha}$., de las que sólo pertenecen al Municipio 29, por pertenecer $5 \mathrm{Ha}$. en proindivisos al Estado, otras $25 \mathrm{Ha}$., como superficie estimada, están parceladas en varias fincas de labor y pasto (24).

En el Municipio de Tejares, la menor entidad de los bienes territoriales municipales, reducida a $69 \mathrm{Ha}$. y $83 \mathrm{~A}$., que significan un 6 por 100 de la superficie del término, está acompañada de la parcelación de la propiedad en 14 terrenos, de los cuales sólo tres superan las $10 \mathrm{Ha}$. (25).

Torresmenudas, con $301 \mathrm{Ha}$. de bienes territoriales, ofrece el índice relativo más alto del partido judicial en relación con la superficie del término, $251 \mathrm{Ha}$; t también ofrece la unidad territorial más extensa, con $223 \mathrm{Ha}$. y $98 \mathrm{~A}$. El resto de las propiedades tiene una entidad media aceptable, con cuatro terrenos de 12, 13, 14 y 23 hectáreas (26). No obstante, el Municipio de Las Veguillas es el que permite apreciar el patrimonio más importante desde el punto de vista cuantitativo y cualitativo del Partido judicial de Salamanca. Sus $708 \mathrm{Ha}$. de bienes comunales le sitúan, aunque no alcanzan el porcentaje relativo en relación a la superficie del Municipio que alcanzó Torresmenudas, que en el Municipio de Las

(22) $B V B N$, 25-I-1860, 29-III-1861, 25-IX-1866 y 4-IV-1894.

(23) $B O P$, suplemento núm. 1859, y $B V B N$, 28-IV-1865 y 20-X-1880.

(24) $B V B N, 17-\mathrm{X}-1873$ y 6-VII-1865.

(25) $B V B N$, 14IV-1856, 22-XII-1860, 7-III-1865, 27-XII-1879, 3-IX-1894 y 6-II-1897.

(26) $B V B N, 29-\mathrm{X}-1859,7-\mathrm{X}-1859,25-\mathrm{I}-1860$ y 22-IX-1887. 
Veguillas se reduce al 16 por 100 , sí permite apreciar unidades territoriales situadas al nivel de 20 a $80 \mathrm{Ha}$., y dos montes de pastizal y roble de $120 \mathrm{Ha}$. cada uno (27).

En el momento de apreciar el significado de los bienes municipales en los 14 Municipios en los que el porcentaje de los bienes territoriales municipales supera el 5 por 100 en relación con la superficie del término municipal, no es posible extraer conclusiones favorables para la entidad de los bienes territoriales de los Municipios. Los Municipios de Arcediano, Doñinos de Salamanca, Mozárbez, Parada de Rubiales, San Cristóbal de la Cuesta y Tejares están gravados en sus propiedades territoriales por una lamentable fragmentación territorial, que adquiere el límite extremo en Arcediano, con 131 unidades de superficie en un total de $113 \mathrm{Ha}$., y en Mozárbez, con 221 unidades territoriales para $287 \mathrm{Ha}$.

Sólo ocho Municipios, de los 14, excluido el Municipio de Salamanca, en los que podía presuponerse un relativo relieve económico de las propiedades territoriales municipales, tienen en las unidades en que se fragmentan sus propiedades una entidad que permite apreciar cierto equilibrio, como fundamento de una viabilidad y una relativa importancia económica. En este sentido es posible afirmar que los Municipios de Aldeanueva de Figueroa, Barbadillo, Calvarrasa de Abajo, Carrascal del Obispo, Florida de Liébana, Pelabravo, Torresmenudas y Las Veguillas son los únicos Municipios del Partido judicial de Salamanca con extensiones medias aceptables y con un volumen conjunto en sus propiedades con algún significado.

No obstante, no es posible establecer aún, como conclusión, que de los 48 Municipios del Partido judicial, excluido el término cabeza de partido, sólo ocho poseen bienes con relativa entidad. Aún es preciso matizar, y de la matización resultará la reducción del número de Municipios cuyas propiedades territoriales estén, en alguna medida, cualificadas. Si consideramos el apéndice número 1 , descriptivo de las distintas unidades territoriales, observaremos cómo las extensiones superficiales mayores coinciden con monte alto o bajo de encina, roble o alcornoque, al que no es ajeno el carrascal o la mata, la piedra suelta o el penascal. Estas peculiaridades matizan, de modo negativo, las propiedades municipales de Las Veguillas y Carrascal del Obispo, cuya

(27) BVBN, 28-VIII-1866 y 18-III-1893. 
orografía está condicionada por las peculiaridades de coincidir con las estribaciones de la sierra, que no contribuye a dotar de calidad a los terrenos. Las propiedades de Florida de Liébana, aunque situadas en las proximidades de la vega del Tormes, presentan el factor negativo de corresponder a una zona que, desde la perspectiva orográfica, corresponde a terrazas de canto rodado, que las invalida para la agricultura y, en notable medida, para la ganadería, excepción hecha de los aprovechamientos de encina para la montanera. En el caso de Torresmenudas concurren las mismas circunstancias que en Florida de Liébana; los residuos de áridos constituyen el sustrato de la zona de monte que limita con la vega del Tormes y, en gran medida, descalifica la importancia económica de los bienes municipales.

En el caso del Municipio de Barbadillo, no puede pasar desapercibido, como elemento cualificante de sus propiedades municipales, el hecho de que importantes superficies están catalogadas (según es apreciable en el apéndice, en el que se relacionan las propiedades y sus características) por la circunstancia de ser montes alto y bajo de encina y carrascales, peculiaridades que no contribuyen a caracterizar positivamente la entidad económica de los bienes municipales del Municipio. Excepción hecha de su posible aprovechamiento en montanera y leña, aprovechamientos que avalaba su condición de comunales.

Las circunstancias señaladas reducen los ocho Municipios en los que las propiedades territoriales tenían cuantitativamente cierta entidad a los Municipios de Aldeanueva de Figueroa, Calvarrasa de Abajo y Pelabravo, en los que concurren las circunstancias de que la entidad cuantitativa de las unidades territoriales y del con'junto de propiedades es complementada con una mínima calidad de las tierras, lejana al carácter residual y marginal de las zonas áridas de las estribaciones de sierra o de depósito de canto rodado en la confluencia de las vegas. La configuración de las propiedades de Aldeanueva de Figueroa, según se puede apreciar en el apéndice en el que se realiza inventario de las propiedades, y su situación en la comarca de la Armuña, son elementos cualificantes no poseídos por otros Municipios, salvo los casos de Calvarrasa de Abajo y Pelabravo, situados en la vega del Tormes, si bien la calidad de sus tierras se califica por los $B V B N$ en segunda y tercera categoría, y sólo Calvarrasa de Abajo posee, con carácter residual, tierras calificadas como de primera. 
En el momento de ofrecer una síntesis valorativa sobre la entidad de los bienes territoriales de los Municipios del Partido judicial de Salamanca es preciso concluir que, excepción hecha de los Ayuntamientos de Aldeanueva de Figueroa, Calvarrasa de Abajo y Pelabravo, el resto de las propiedades territoriales de los Municipios carece de cualificación a nivel económico $\mathrm{y}$, sin duda, son elementos marginales dentro de la actividad económica, reduciéndose, en el mejor de los casos, su importancia a proporcionar algunos ingresos económicos a las municipalidades, cuyo nivel de actividad no era, sin duda, muy elevado, o algunas prestaciones económicas a los vecinos.

Finalmente, en relación con el Municipio de Salamanca, resaltan unas peculiaridades que le confieren una personalidad especial sin duda ligada a la circunstancia de ser el Municipio cabeza del Partido judicial.

En primer término destaca el hecho de que posea bienes de propios en otros Municipios de su partido. En segundo término resalta el hecho de que participe en proindivisos de propiedades rústicas pertenecientes a Municipios del Partido judicial. Finalmente llama la atención el que sea el único Municipio que posea censos rústicos y urbanos (28). Los Municipios de Arcediano, Aldearrodrigo, Barbadillo, Castellanos de Moriscos, Encinas de Abajo, Gomecello, Palencia de Negrilla, San Cristóbal de la Cuesta y Topas tienen en sus respectivos términos municipales bienes de propios del Municipio de Salamanca, con la particularidad de su escasa entidad superficial, situada, en la mayor parte de los casos, por debajo de la hectárea (29). Sólo superan la hectárea una de las tierras en Encinas de Abajo y los bienes del Municipio de Salamanca localizados en Aldearrodrigo, de los que únicamente hemos podido localizar el Boletín de Venta, desconociendo la extensión superficial, que se puede considerar estimable conforme al precio medio de las transacciones habidas en los bienes subastados de Aldearrodrigo, pudiendo equivaler a una superficie situada en torno a las $34 \mathrm{Ha}$.

Mayor significado económico tienen los proindivisos poseídos en Barbadillo (Valverde de Valmuza) y Topas (Cardeñosa), con partes, respectivamente, de un cuarto y un quinto en superficies tỏtales de 543 y $844 \mathrm{Ha}$. (30).

(28) $B V B N, 14-1 \mathrm{I}-1862$.

(29) $B V B N$, 9-IX-1859, 4II-1860, 15-XI-1860, 16-II-1861, 19 у 29-III-1861 y 9-IX-1861.

(30) $B V B N, 25-\mathrm{I}-1860$ y $15-\mathrm{XI}-1860$. 
Las propiedades rústicas poseídas en el mismo término municipal carecen de entidad económica; se reducen a ocho terrenos, ninguno de los cuales supera la hectárea de superficie. No obstante, no puede ser ignorada la importancia de la propiedad titulada "El Marín», denominación que en la actualidad se conserva, con una extensión de $336 \mathrm{Ha}$. y $64 \mathrm{~A}$., situada en una zona de la vega baja del río Tormes, y que poseía un notable significado económico por la coincidencia afortunada de una calidad media de tierra apreciable y su condición de vega (31). Las posesiones urbanas no tienen especial entidad, excepción hecha del terreno de «El Calvario", situado en las afueras de San Bernardo, con una superficie de $4.270 \mathrm{~m}^{2}$; un edificio colindante con el Ayuntamiento, con superficie de $615 \mathrm{~m}^{2}$, y cinco partes de las 93, proindivisas, de la Plaza de Toros. El resto de las propiedades urbanas subastadas se reducían a una bodega-alhóndiga, de $155 \mathrm{~m}^{2}$; un solar en el "Monte Olivete», de $41 \mathrm{~m}^{2}$; un «cuadro» en la parroquia de Santiago, de $66 \mathrm{~m}^{2}$, y un "portal» en la calle de la Rúa, de 11,79 $\mathrm{m}^{2}$ (32).

\section{CONSIDERACION SOBRE LA CALIDAD DE LA TIERRA EN LOS BIENES DESAMORTIZADOS}

Con base en los datos que aportan los Boletines de Venta, que clasifican las tierras en cuatro categorías (primera, segunda, tercera y pedregal o erial), la conclusión a la que se puede llegar sobre la calidad media de la tierra en las propiedades municipales desamortizadas se concreta en su baja calidad. La mayor parte de las estimaciones sitúan las calidades al nivel de segunda y tercera categoría, y sólo de modo residual se constata la existencia de tierras de primera categoría. En los 49 Municipios considerados sólo hemos podido localizar superficies de primera categoría con alguna importancia en parte de las propiedades subastadas de Calvarrasa de Abajo, Carrascal del Obispo y San Cristóbal de la Cuesta. En el resto de los Municipios únicamente son constatables superficies residuales de primera. En este caso se encuentra Arapiles, con una superficie de alrededor de $2.000 \mathrm{~m}^{2}$ en un conjunto de $21 \mathrm{Ha}$. de bienes subastados; Carbajosa de la Sagrada, con una pequeña ala-

(31) $B V B N, 7-\mathrm{IX}-1861$.

(32) $B V B N$, 9-IX-1859, 17-IX-1859, 21-I-1860, 2-II-1862 у 23-IX-1892. 
meda; Castellanos de Moriscos, con una superficie de 4 A.; Moriscos, con otra pequeña superficie de 4 A.; Mozárbez y Parada de Arriba, donde, según los Boletines de Venta, "hay algo de primera clase», y Calvarrasa de Abajo, San Pedro de Rozados, Santa Marta y Las Torres, donde, de modo residual, se individualizan algunas superficies de primera.

\section{ESTIMACION SOBRE LOS VALORES ALCANZADOS EN LA ADJUDICACION DE LAS PROPIEDADES MUNICIPALES SUBASTADAS $\left({ }^{*}\right)$}

Como estimación general, y de acuerdo con la relación que acompañamos, es posible afirmar que los valores de adjudicación han sido altos en relación, al menos, con los valores de tasación y salida a subasta. La tónica media de las adjudicaciones supera ampliamente los tipos de salida y se sitúa con facilidad, en muchos casos, en torno al 2006300 por 100 . Sólo de modo excepcional es posible encontrar casos de adjudicaciones a la par, y aún más excepcionales son los casos de segundas subastas por falta de postores o quiebras.

De las 152 transacciones registradas, el número de transacciones a la par no alcanza la veintena, afectando a ocho Municipios. Los Municipios afectados son los siguientes: Barbadillo, con una propiedad de superficie en torno a una hectárea, subastada en 1878; Calvarrasa de Abajo, en relación con una propiedad de $76 \mathrm{Ha}$., subastada en 1859; Cilleros el Hondo, con una propiedad parcelada en 12 pedazos de tierra con superficies entre $4 \mathrm{~A}$. y $2 \mathrm{Ha}$., subastada en 1863; Mozárbez, con cuatro transacciones, realizadas las tres primeras en 1859 y la última en 1870, y que afectan a un lote de 13 tierras, con superficie de $6 \mathrm{Ha}$; lote de 15 tierras, con superficie de $7 \mathrm{Ha}$.; una alameda de $3 \mathrm{~A}$., y un lote de cinco tierras, con superficie de 70 Ha.; San Cristóbal de la Cuesta, con una propiedad de $34 \mathrm{Ha}$., enajenada en 1874; Villamayor, con dos terrenos, marginales, de 65 A., adjudicado en 1864, y 3 A., adjudicado en 1872, y, finalmente, Las Veguillas, que registra el dato de que importantes superficies, que oscilan entre 26 y $55 \mathrm{Ha}$., son adjudicadas a la par en 1866, no constando, en contra de la norma habitual, en los

(`) Base Documental, apéndice núm. 1. 
Boletínes de Ventas de Bienes Nacionales el nombre del adjudicatario. La adjudicación a la par, la ausencia de individualización de adjudicatario y el dato cuantitativo de la importancia de las superficies provocan una situación atípica, cuyo estudio particularizado tendría interés especialmente en conexión con algunas extensas propiedades particulares actualmente existentes en ese término municipal.

El Municipio de Salamanca también se vio afectado por una adjudicación a la par en la subasta de cinco partes, proindivisas, del condominio de la Plaza de Tóros.

Advertimos cómo la diversidad de fechas en las transacciones relacionadas, así como las distintas localizaciones territoriales, no permiten obtener conclusiones sobre las posibles causas que pudieron concurrir en las bajas cotizaciones.

Como índice revelador de las altas cotizaciones alcanzadas en las subastas es posible registrar alrededor de 20 transacciones que superan el 500 por 100 de la base inicial y que, en algún caso, alcanzan el 1.000 y el 2.000 por 100 .

Entre el 500 y el 600 por 100 es posible registrar adjudicaciones en Carbajosa de la Sagrada (585 por 100 en finca de $19 \mathrm{Ha}$.), Cilleros el Hondo ( 577 por 100 en finca de $2 \mathrm{Ha}$.), Doñinos de Salamanca (559 por 100 en finca de $41 \mathrm{Ha}$.), Miranda de Azán ( 500 por 100 en finca de $1 \mathrm{Ha}$ y $65 \mathrm{~A}$. y 564 por 100 en finca de $1 \mathrm{Ha}$. y $63 \mathrm{~A}$.).

Entre el 600 y 700 por 100 se encuentran las siguientes transacciones: Parada de Rubiales (668 por 100 , dos tierras que suman en superficie $40 \mathrm{Ha}$.), Pajares de la Laguna (615 por 100, 18 tierras cuyas superficies mayores eran de 4, 6 y $20 \mathrm{Ha}$., y el resto irrelevante) y Topas (640 por 100 , perteneciente a los propios de Salamanca, materializados en un quinto, proindiviso, de $844 \mathrm{Ha}$.).

Al nivel situado entre el 700 y 800 por 100 de incremento sobre la base inicial se encuentran las transacciones siguientes: Castellanos de Villiquera ( 779 por 100 , superficie de $14 \mathrm{~A}$. y 53 ca.) y Villaverde de la Guareña ( 746 por 100 , superficie de 2 A. y 74 ca.). Alcanzó el nivel situado entre el 800 y 900 por 100 la transacción registrada en Forfoleda ( 894 por 100, con superficie de 7 A. y 26 ca.).

Entre el 900 y el 1.000 por 100 se sitúan: Castellanos de Moriscos (900 por 100, superficie de 4 A. y 20 ca.), Parada de Rubiales (1.000 por 100 , con superficie de $12 \mathrm{Ha}$., que implicaba nueve tierras) y Topas (900 por 100, con superficie de 10 A. y 96 ca.). 
Supera el 1.000 por 100 una transacción registrada en Mozodiel de Sachinigo (1.227 por 100, con superficie de $9 \mathrm{Ha}$.).

Por encima del 2.000 por 100 las transacciones registradas en Gomecello (2.933 por 100, en casa situada en el casco del pueblo, de $22 \mathrm{~m}^{2}$ y $89 \mathrm{~cm}^{2}$ de superficie) y Tejares (2.113 por 100 , en superficie de 86 A. y 75 ca.). El nivel de 2.382 por 100 es el alcanzado por una superficie de $55 \mathrm{Ha}$. en el término municipal de Las Veguillas, cotización que, sin duda, se margina de las adjudicaciones a la par que definieron las subastas en este Municipio. Todas las transacciones de que hemos hecho mención y que alcanzan los mayores porcentajes relativos en el nivel de adjudicación sobre la base de subasta se extienden por los diversos años que comprende el período desamortizador, no pudiéndose relacionar con ningún período determinado. Llama, sin embargo, la atención los altos porcentajes alcanzados por superficies muy pequeñas; preciso es que hagamos notar que estas superficies corresponden, por lo general y como puede comprobarse en la relación que adjuntamos, a alamedas; en otras palabras, se puede decir que corresponden a los pequeños productos de vegetación arbórea que los términos municipales poseían para uso del común de los vecinos. Estas altas cotizaciones de las alamedas, sin duda, hay que situarlas en conexión con la desarborización de Castilla y quizá con una incipiente estimación de un nivel de vida relacionado con el árbol como bien escaso. No obstante, parece obligado matizar esta última afirmación por el hecho de que los $B V B N$ suelen ofrecer una estimación económica de los árboles y plantones incluidos en las alamedas conectada con su presunto valor en corta.

La falta de adjudicación en primera subasta, bien por falta de licitadores o bien por quiebra de los iniciales adjudicatarios, son residuales. Sólo hemos podido registrar una quiebra registrada en relación con dos adjudicaciones de una superficie de 14 y $36 \mathrm{Ha}$. en Pelabravo (33), y la celebración de segunda subasta en Salamanca en relación con una cuadra, localizada en la parroquia de Santiago, con superficie de $67 \mathrm{~m}^{2}$, y que fue adjudicada en un 194 por 100 sobre el tipo inicial (34). A tercera subasta se llega en el caso de dos propiedades, también pertenecientes a los propios del Municipio de Salamanca: un solar, situado en el denominado «Mon-

(33) $B V B N, 21-V I I-1859$.

(34) $B V B N, 9 . \mathrm{XI}-1859$. 
te Olivete», de $44 \mathrm{~m}^{2}$ de superficie, y la alhóndiga, situada en la Plazuela de la Cárcel, de $155 \mathrm{~m}^{2}$ de superficie, y que es adjudicada por precio muy próximo al de tasación en primera subasta (35).

\section{OBSERVACIONES EN RELACION CON LOS ADJUDICATARIOS DE LAS PROPIEDADES SUBASTADAS $(*)$}

En el apéndice documental en el que nos basamos es posible observar, como dato más significativo, el relativo a la normal correlación que existe entre la localización de la propiedad subastada y la residencia del adjudicatario. En algunos casos en que parece encontrar excepción esta nota dominante, la excepción se encuentra minorada por la circunstancia de que el adquirente tiene su residencia en un término municipal limítrofe, circunstancia que permite, a efectos prácticos, identificar la localización de propiedades y residencia del adjudicatario. En este caso se encuentran adquisiciones que implican a propiedades situadas en Cabrerizos y adquiridas por un residente en Villares de la Reina (núm. 12 de la relación), o la correlación de los términos municipales de Arapiles, Miranda de Azán, Mozárbez y Valdemierque (núms. 55, 58, 59, 62, y 64 de la relación). Al margen de la constante mencionada que permitiría extraer la idea de que las propiedades subastadas fueron, en su mayoría, adquiridas por residentes en los mismos términos municipales de las propiedades subastadas o bien en Municipios limítrofes, se deja sentir la influencia de residentes en la capital provincial. De los 78 casos considerados, en los que ha sido posible individualizar a los adjudicatarios y su residencia, 37 adquisiciones implican a residentes en el término municipal de Salamanca. Sin duda, es posible estimar, confirmando de este modo viejos postulados económicos, que el centro económico más importante actúa como polarizador de las unidades económicas menos importantes de su entorno. No obstante, también se registra en este caso el dato de que varias de las adquisiciones de residentes en Salamanca se realizan sobre términos municipales limítrofes al Municipio de Salamanca. En esta circunstancia se encuentran adquisiciones de propiedades en Arapiles (núms. 8 y 9), en Cabrerizos (núm. 13),

(35) BVBN, 9-IX-1859.

(*) Base Documental, apéndice núm. 2. 
Tejares (núm. 35) y Villamayor (núm. 40). La incidencia de no residentes en el Partido judicial de Salamanca en la adquisición de los bienes del partido subastados se reduce a la presencia, sin duda inevitable, de tres adquirentes con residencia en Madrid, a los que le son adjudicados bienes en Calvarrasa (núm. 15), Miranda de Azán (núm. 56) y una finca urbana en el mismo término municipal de Salamanca (núm. 52). En estos tres casos se confirma la regla económica precitada y el ascendiente sobre su entorno.

Como conclusión, parece posible afirmar que la dinámica de las adquisiciones de las propiedades subastadas no supera el ámbito del Partido judicial de Salamanca. La oferta simultánea de tierras en todo el territorio nacional y el incipiente desarrollo de un capitalismo financiero de la época tenían que reducir las expectativas suscitadas por la enajenación de los bienes desamortizados a unidades económicas muy integradas. En función de esta circunstancia, es explicable la correlación existente entre localización de propiedades y residencia de los adjudicatarios. Como corolario, es posible constatar las pocas sugerencias que provoca la relación nominativa de adjudicatarios, que, si en algún momento recuerdan a apellidos en alguna medida destacados en la historia provincial (Mazpule, Cea, De la Riva, De la Rúa, Polo, Calama...), como tónica general reflejan apellidos muy comunes, sin duda ligados a propietarios agrícolas o pecuarios. A nivel, casi anecdótico, únicamente es constatable la existencia de un título nobiliario, el Vizconde de Revilla, residente en Salamanca y al que le fueron adjudicadas propiedades en Castellanos de Villiquera (núm. 20).

El acaparamiento de propiedades, como lógica consecuencia de lo expuesto, no pudo tener lugar. En los pocos casos en que es posible registrar repetición en los nombres de los adjudicatarios concurre la circunstancia de afectar a propiedades que o bien están en el mismo término municipal (caso de Francisco Polo, con dos adquisiciones en San Cristóbal de la Cuesta, núms. 30 y 43), o bien en términos colindantes (caso de José MORENo CEA, con adquisiciones en Miranda de Azán y Mozárbez, núms. 61 y 71, y caso de Angel Calama, con la adquisición de "El Marín», en el término municipal de Salamanca, y adquirente de propiedades en los términos colindantes entre sí de Carrascal de Barregas y Parada de Arriba, núms. 50 y 51). 


\section{CORRELACION ENTRE BIENES DE PROPIOS Y BIENES COMUNALES EN LAS PROPIEDADES MUNICIPALES DESAMORTIZADAS $\left({ }^{*}\right)$}

Con los datos aportados por los Boletines de Venta no es posible llegar a una estimación exacta sobre la vinculación de los bienes subastados a la categoría de bienes de propios, generativos de renta para los Municipios, o bienes comunales, destinados a la exclusiva utilización por el común de los vecinos (36). Los Boletines de Ventas, a partir de 1889, no particularizan si los bienes subastados eran de propios o comunales. Por esta causa, en los Municipios de Arcediano, Calvarrasa de Arriba, Carbajosa de la Sagrada, Pedrosillo el Ralo, San Cristóbal de la Cuesta, San Pedro de Rozados, Tejares, Las Torres, Villares de la Reina y Villaverde de la Guareña no es posible llegar a individualizar la relación bienes de propios-bienes comunales.

En referencia al resto de los Municipios, el equilibrio bienes comunales y de propios se desplaza a favor de los bienes comunales. En términos absolutos, hay un predominio de Municipios cuyos bienes estaban, en su mayoría, definidos como comunales, 24 Municipios sobre los 38 de los que se poseen datos; nueve de los Municipios (Aldeatejada, Carrascal de Barregas, Castellanos de Moriscos, Castellanos de Villiquera, Espino de la Orbada, Forfoleda, Monterrubio de la Armuña, Topas y Valverdón) poseen superficies comunales de muy pequeña extensión y prácticamente irrelevantes, y otros tres Municipios (Gomecello, Miranda de Azán y Villamayor), que llegan a alcanzar 7, 5 y $4 \mathrm{Ha}$. de bienes comunales, están afectados, de modo negativo en el momento de tratar de valorar estos bienes,

(*) Base Documental, apéndice núm. 3.

(36) Sobre el proceso de distinción entre bienes comunales y bienes de propios y la relatividad de su distinción conceptual, vid. el precitado trabajo de GARCfA DE ENTERRfA: «Las formas comunitarias de propiedad forestal y su posible proyección futura». Anuario de Derecho Civil, Madrid, 1976, págs. 283-289. Hacemos la observación de que la Ley desamortizadora de 1 de mayo de 1855 no utiliza el término "comunal» a efectos de la posible exclusión de la venta de bienes impuesta por la normativa desamortizadora, utiliza la expresión «terrenos que son hoy de aprovechamiento común», remitiendo, por la explícita referencia impuesta por el vocablo «hoy", como inexcusable referencia al momento de promulgación de la Ley, a una situación fáctica notablemente relativizadora de la distinción entre bienes de propios y bienes comunales. Sobre el origen, evolución y prospectiva de los bienes comunales, vid., por todos, NIEto: Bienes comunales, Madrid, 1964. 
por la circunstancia de estar muy fragmentadas las propiedades que llegan a constituir las superficies citadas.

Los Municipios con cierta entidad en sus bienes comunales se concretarán en los 14 Ayuntamientos siguientes: Barbadillo (177 hectáreas), Calvarrasa de Abajo (176 Ha.), Carrascal del Obispo (500 Ha.), Doñinos de Salamanca ( $85 \mathrm{Ha}$.), Florida de Liébana (146 hectáreas), Galindo y Perahuy (115 Ha.), Mozárbez (185 Ha.), Pajares de la Laguna (37 Ha.), Parada de Arriba (65 Ha.), Pelabravo (73 Ha.), Torresmenudas (253 Ha.) y Las Veguillas (708 Ha.).

De los 14 Municipios en los que predominan los bienes de propios, cuatro tienen una relativa entidad: Aldeanueva de Figueroa (344 Ha.), Cilleros el Hondo (65 Ha.), Parada de Rubiales (326 Ha.) y el Ayuntamiento de Salamánca ( $735 \mathrm{Ha}$.). Los 10 Municipios restantes poseían un discreto patrimonio de bienes calificados como de propios: Aldealengua (18 Ha.), Aldearrubia (55 A.), Aldeaseca (3 Ha.), Arapiles (14 Ha.), Cabrerizos (3 Ha.), Calzada de Valdunciel (8 Ha.), Moriscos (4 Ha.), Palencia de Negrilla (8 Ha.) y Santa Marta (17 Ha.).

La conclusión a la que podemos llegar se materializa en la mayor entidad, absoluta y relativa, de los bienes calificados como comunales en relación con los bienes calificados como de propios, salvado el dato de que del total de los 49 Municipios que estudiamos, en un total de 11 no hemos podido llegar a concretar, como hicimos constar, la pertenencia de los bienes a las categorías de propios o comunales.

Otro factor relativizador está constituido por las observaciones hechas en el primer capítulo de este trabajo, y la incidencia negativa que para las extensiones superficiales globales de que hemos hecho mención significa la sensible fragmentación de las unidades superficiales que las integran.

El predominio de los bienes comunales sobre los bienes de propios está justificado si se considera que, salvo el Ayuntamiento de Salamanca, el resto de los Ayuntamientos operan en una economía agropecuaria en la que los bienes comunales encuentran más adecuada inserción que los bienes de propios. Esta apreciación encuentra confirmación si se considera que el Ayuntamiento con un patrimonio de bienes de propios más importante es el Ayuntamiento de Salamanca, operante en un sector que se sustrae de la órbita agrícola-pecuaria para integrarse en el sector servicios, en el que los bienes de propios, como generadores de renta, encuentran un 
más adecuado engarce. No obstante, y a pesar de las apreciaciones hechas, queda por dilucidar la causa por la que los bienes comunales fueron enajenados y llegaron a alcanzar tan altos precios.

\section{ESTIMACION ACTUAL DEL PATRIMONIO INMOBILIARIO DE LOS MUNICIPIOS PERTENECIENTES AL PARTIDO JUDICIAL DE SALAMANCA $\left(^{*}\right)$}

La estimación del patrimonio inmobiliario poseído en la actualidad por los Municipios pertenecientes al Partido judicial de Salamanca, encuentra justificación en la circunstancia de que no se puede establecer correlación exacta entre los bienes desamortizados y los bienes que constituían el patrimonio municipal. Si el artículo 1..$^{\circ}$ de la Ley General Desamortizadora de 1 de mayo de 1855 dispuso la venta de los predios rústicos y urbanos y de los censos y foros pertenecientes a los de propios y comunales de los pueblos, el artículo $2 .^{\circ}, 9$, del mismo texto legal neutralizaba parte de los efectos de su artículo precedente, previendo que pudieran ser exceptuados los terrenos "que son hoy de aprovechamiento común", con audiencia del Ayuntamiento afectado y de la Diputación Provincial, correspondiendo la decisión al Gobierno, que en el caso de desacuerdo con el Ayuntamiento debería oír al Tribunal Contencioso-administrativo. La Ley de 30 de junio de 1856 amplía la excepción contenida en el artículo $20^{\circ}$ de la Ley de 1855 , incluyendo en su ámbito las dehesas destinadas o que se destinasen al pasto de ganado de labor perteneciente a los vecinos del Municipio. Se atribuía al Gobierno el fijar la extensión de la dehesa, atendidas las necesidades de cada pueblo, con audiencia del correspondiente Ayuntamiento y de la Diputación Provincial. Ambas excepciones son confirmadas en su vigencia por la Ley de 8 de mayo de 1888, y para su adecuada aplicación se dictó la Instrucción de 21 de junio de 1888.

Al amparo de las excepciones citadas es evidente que, bien a petición del Ayuntamiento o bien a petición de los vecinos (observemos que el precepto concede audiencia al Ayuntamiento, sin mencionar su competencia exclusiva para solicitar la excepción), los patrimonios municipales podían haber salvado parte de sus bienes

(*) Base Documental, apéndice núm. 4. 
comunales e incluso formalizar la calificación como comunales de determinados bienes al amparo de los textos legales citados, lo que equivale a afirmar que no hay correspondencia entre bienes desamortizados y patrimonio municipal, al margen de la excepción de la normativa desamortizadora de los bienes de servicio público (casa consistorial, escuela, cementerio...).

Por esta razón hemos tratado de evaluar los patrimonios municipales del Partido, considerando tanto los que fueron objeto de la normativa desamortizadora y los que no fueron afectados por ella (no podemos olvidar que los 49 Municipios estudiados equivalen al 67 por 100 de los Municipios del Partido judicial, en el que se integran 63 Municipios). La finalidad de esta evaluación se realiza a efectos de ratificar o corregir las apreciaciones hechas sobre los bienes desamortizados. Operando sobre una muestra de 23 Municipios que sufrieron desamortización y seis Municipios cuyos nombres están ausentes de los Boletines de Ventas, podemo avanzar el dato de que las observaciones hechas sobre los bienes desamortizados, identificándolos con los patrimonios municipales, no encuentra correctivos en las excepciones que pudieron derivar del artículo $2 .^{\circ}$ de la Ley de 1855 , complementado por la modificación de que es objeto este precepto por la Ley de 1856. De la muestra de Municipios desamortizados excluimos el Municipio de Salamanca al concurrir en él unas peculiaridades que eliminan la homogeneidad de circunstancias necesarias para ser comparado con otros Municipios del Partido al margen de esta exclusión y de dejar constancia de que nuestro deseo hubiera sido poder operar con datos de la totalidad de los Municipios del Partido; estimamos que la muestra utilizada para evaluar los actuales patrimonios municipales es significativa, ya que representa el 46 por 100 de los Municipios desamortizados y el 44 por 100 de los Municipios no afectados por la desamortización; de modo complementario, los Municipios de la muestra cubren ampliamente el espectro geográfico del Partido judicial.

Entre los 23 Municipios que fueron desamortizados, cuatro poseen bienes calificados como comunales. Los Municipios de Arcediano, Calzada de Valdunciel, Pino de Tormes y Villamayor. El resto de los Municipios carecen de bienes comunales, tanto los desamortizados como los no desamortizados.

No obstante, y en relación con los cuatro Municipios mencionados, es posible hacer las siguientes observaciones: en primer tér- 
mino, el carácter marginal de los bienes comunales de Pino de Tormes, limitados a un pastizal de $1 \mathrm{Ha}$. y 59 A.; a ello se añade la apreciable fragmentación, en cinco prados y dos alamedas, de las $25 \mathrm{Ha}$. pertenecientes al Municipio de Arcediano como circunstancia que relativiza la entidad y operatividad de los bienes y la desvirtuación del estricto carácter de los bienes comunales (aprovechamiento exclusivo al servicio del común de los vecinos) en los Municipios de Calzada de Valdunciel y Villamayor; el primero de los Municipios por el destino a cultivo agrícola del, sin duda, importante patrimonio, al menos en su aspecto cuantitativo ( $240 \mathrm{Ha}$.), del Municipio, circunstancia que transforma al bien comunal en simple generador de renta, identificándose, a efectos operativos, con los bienes de propios. En el caso de Villamayor, por el destino a huertos familiares de la más importante superficie de sus presuntos bienes comunales y el arrendamiento de $6 \mathrm{Ha}$. de pastizales, inicialmente calificados como comunales. En contraste con la desvirtuación de los bienes comunales en los Municipios referidos, es posible registrar la práctica operatividad como comunales de cuatro prados de un total de cinco, cuya superficie alcanza las $71 \mathrm{Ha}$. en el Municipio de Tardáguila al destinarse los cuatro prados mencionados a aprovechamiento por los vecinos.

De la observación de los bienes poseídos por los Municipios, de los que hemos podido obtener datos sobre su patrimonio, creemos apreciar la marginalidad de los bienes comunales, con la excepción de Calzada de Valdunciel, que parece haber hecho uso (hacemos constar que no nos ha sido posible verificar esta hipótesis) de las posibilidades ofrecidas por el artículo $2 .^{\circ}$ de la Ley de 1855 , al excepcionar sus bienes municipales de la desamortización, si se considera que los bienes enajenados a este Municipio, en el período 1855-1911, se redujeron, según se hace constar en el apéndice núm. 3, a 8 Ha. y 64 ca. de bienes de propios.

También es importante el patrimonio municipal de Tardáguila, que califica, como bienes de propios, 59 fincas, cuya superficie alcanza las $250 \mathrm{Ha}$.; cinco prados, con una superficie conjunta de $71 \mathrm{Ha}$., y dos montes de 15 y $80 \mathrm{Ha}$. Los Municipios de Barbadillo, con $67 \mathrm{Ha}$. de bienes de propios; Espino de la Orbada, con cerca de $200 \mathrm{Ha}$., divididas en 36 parcelas; Carrascal del Obispo, con $109 \mathrm{Ha}$., parecen constituir la excepción a unos patrimonios municipales que, más por inercia que por voluntad, se reconstruyen con 
base en las «masas comunes» resultantes de la concentración parcelaria, legados testamentarios y abandonos de tierras.

Lo bienes de propios referidos, todos ellos de carácter rústico, son, por lo general, objeto de arrendamientos por periodos anuales en pública subasta, incidiendo, sobre esta modalidad de obtención de rentas, el sensible receso del sector agrícola y pecuario, materializable en el espectacular cambio de coyuntura económica que ha registrado el campo al pasar del «hambre de tierras» al abandono de tierras. El patrimonio inmobiliario urbano de los Municipios en los que nos ha sido posible obtener datos corrobora una lamentable situación de unas unidades económicas, respecto de las cuales los responsables de la política económica parecen permitirse el costoso lujo de poder prescindir. Las relaciones de bienes urbanos facilitadas por los Secretarios de los Ayuntamientos (37), después de detallar la superficie, alturas y circunstancias de la casa consistorial, hacen referencia a solares, ruinas o edificios en mal estado de lo que fueron escuelas o mataderos municipales, a las ruinas o solares de lo que fueron corrales del Concejo o al frontón municipal en mal estado de conservación..., permitiendo entrever un progresivo asolaramiento del que sólo se marginan los Municipios absorbidos por la capital provincial.

\section{CONSIDERACIONES FINALES}

En el momento de ofrecer unas consideraciones finales sobre la incidencia de la desamortización en los bienes de los Municipios del Partido judicial de Salamanca, es posible poder ofrecer algunas ideas que estimamos compendian la problemática de la desamortización sobre los bienes estudiados.

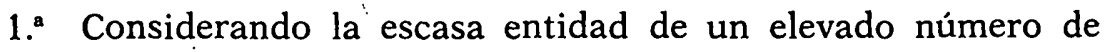
patrimonios municipales, puede afirmarse que la desamortización de los bienes municipales estaba ya prácticamente hecha en el Partido judicial de Salamanca en 1855. Recordemos el dato de que en-

(37) En las relaciones de bienes municipales facilitadas por los Secretarios de los Ayuntamientos es posible apreciar que califican como bienes de propios, fundamentalmente definidos por el artículo 186 de la Ley de Régimen local como generadores de ingresos para los Municipios, con los bienes de servicio público, que el artículo 185 del mismo texto legal define como los destinados al cumplimiento de fines de interés público, ejemplificando el artículo 185 con las casas consistoriales, mataderos, escuelas, mercados... Bienes que en muchos inventarios municipales se califican, de modo erróneo, como ade propios». 
tre los 49 Municipios afectados por la desamortización, 31 de ellos, equivalentes al 63 por 100 de estos Municipios, no alcanzaban en sus patrimonios municipales el nivel cuantitativo del 3,5 por 100 de su superficie municipal, y tanto en el caso de los Municipios que no alcanzan ese porcentaje como en los Municipios que lo superan, la fragmentación de las propiedades municipales y la baja calidad de las tierras relativiza la posible operatividad funcional de los bienes municipales.

2. $\quad$ La notable fragmentación de las masas patrimoniales que integran tanto los bienes de propios como los bienes comunales, divididos en un elevado número de parcelas, denota que los patrimonios municipales parecen constituidos más por circunstancias fortuitas (legados testamentarios, tierras abandonadas o sin dueño, ocupación por débitos municipales...) que por su tradicional y habitual integración en la economía del Municipio.

3. ${ }^{a} \quad$ Como consecuencia, y prueba, de la carencia de integración de los bienes comunales y de propios en la economía municipal es posible aportar los significativos datos de las altas cotizaciones alcanzadas por los lotes subastados y la adquisición de las tierras subastadas por vecinos de los mismos términos municipales o por vecinos de los términos municipales colindantes. Estimamos que ambos datos permiten apreciar la carencia de funcionalidad de las tierras subastadas para los mismos residentes en los términos municipales en su calidad de beneficiarios directos de la utilización de los bienes comunales o de beneficiarios indirectos de los ingresos económicos que los Ayuntamientos pudieran recibir de los bienes de propios.

4. ${ }^{a} \quad$ La estimación realizada sobre los actuales patrimonios de los Municipios afectados por la desamortización nos permite concluir que los Municipios con una masa patrimonial más importante de bienes comunales (Barbadillo, Calvarrasa de Abajo, Carrascal clel Obispo, Doñinos de Salamanica, Florida de Liébana, Galindo y Perahuy, Mozárbez, Pelabravo...) no hicieron uso de las posibilidades ofrecidas por el artículo $2 .^{\circ}$ de la Ley de 1 de mayo de 1855 , ampliado por el artículo $1 .^{\circ}$ de la Ley de 11 de julio de 1856 . Con base en los textos legales citados, los Municipios podían haber exonerado sus bienes comunales de la desamortización e incluso reclasificar los bienes a efectos de considerarlos como comunales o crear dehesas boyales. No obstante, permitieron que sus tierras o montes pasaran a integrarse en los patrimonios privados de sus vecinos. El 
dato de que los Ayuntamientos y los vecinos (ya que la reserva de exoneración correspondía tanto a la Corporación municipal como a sus vecinos) hicieran caso omiso de las posibilidades ofrecidas por los textos legales de 1855 y 1856 constituye, a nuestro juicio, un índice más de la carencia de integración en la economía de los Municipios de los bienes comunales, carencia de integración que si es escasa en los bienes comunales encuentra más motivos para incrementarse en los bienes de propios, si se piensa que las posibles rentas a recibir por los Ayuntamientos con base en los bienes de propios reduce su posible virtualidad a la integración económica en unos presupuestos municipales que no requerían demasiada entidad, teniendo en consideración el bajo nivel de demanda de prestaciones y servicios colectivos en las comunidades agropecuarias en la segunda mitad del pasado siglo.

\section{APENDICES}

\section{APÉNDICE NƯMERO 1}

Relación de bienes municipales desamortizados, con expresión de la superficie total de los lotes subastados, constancia de la cantidad en que fueron tasados, cantidad en que fueron adjudicados, porcentaje de variación entre tasación y adjudicación y año de adjudicación.

\section{ALDEALENGUA}

\begin{tabular}{|c|c|c|c|c|}
\hline & Tasación & Adjudicación & $\%$ & Año \\
\hline $\begin{array}{l}\text { Ha. y } 39 \text { A. (siete tierras). } \\
\text { A. y } 32 \text { ca. (alameda) ... }\end{array}$ & $\begin{array}{l}4.965 \text { rs. } \\
6.000 \text { rs. }\end{array}$ & $\begin{array}{l}19.500 \text { rs. } \\
14.100 \text { rs. }\end{array}$ & $\begin{array}{l}393 \\
203\end{array}$ & $\begin{array}{l}1859 \\
1866\end{array}$ \\
\hline
\end{tabular}

ALDEANUEVA DE FIGUEROA

\begin{tabular}{|c|c|c|c|c|}
\hline & Tasacion & Adjudicación & $\%$ & $A \tilde{n} o$ \\
\hline $\begin{array}{rrrrrrrrr}140 & \mathrm{Ha} & \ldots & \ldots & \ldots & \ldots & \ldots & \ldots & \ldots \\
57 & \mathrm{Ha} . & \ldots & \ldots & \ldots & \ldots & \ldots & \ldots & \ldots \\
18 \mathrm{Ha} & \ldots & \ldots & \ldots & \ldots & \ldots & \ldots & \ldots \\
15 \mathrm{Ha} & \ldots & \ldots & \ldots & \ldots & \ldots & \ldots & \ldots \\
17 \mathrm{Ha} . & \ldots & \ldots & \ldots & \ldots & \ldots & \ldots & \ldots \\
8 \mathrm{Ha} & \ldots & \ldots & \ldots & \ldots & \ldots & \ldots & \ldots \\
38 \mathrm{Ha} & \ldots & \ldots & \ldots & \ldots & \ldots & \ldots & \ldots \\
557 & \text { encinas } & \text { (vuelo) } & \ldots & \ldots & \ldots \\
5 & \ldots & \ldots & \ldots\end{array}$ & $\begin{array}{l}62.500 \text { rs. } \\
37.500 \text { rs. } \\
13.800 \text { rs. } \\
10.290 \text { rs. } \\
3.860 \text { rs. } \\
8.400 \text { rs. } \\
12.500 \text { rs. } \\
941 \text { pts. }\end{array}$ & 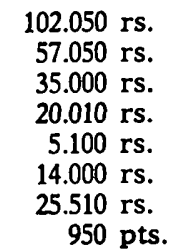 & $\begin{array}{l}163 \\
152 \\
254 \\
194 \\
132 \\
166 \\
200 \\
100,53\end{array}$ & $\begin{array}{l}1864 \\
1864 \\
1864 \\
1864 \\
1864 \\
1864 \\
1869 \\
1872\end{array}$ \\
\hline
\end{tabular}




\section{ALDEARRUBIA}

55 А. у 35 са. ... ... ........ $\frac{\text { Tasación }}{3.850 \text { rs. }} \frac{\text { Adjudicación }}{13.010 \text { rs. }} \frac{\%}{377} \frac{\text { Año }}{1861}$

ALDEATEJADA

4 A. у 35 са. ... ... ... ..... $\frac{\text { Tasación }}{500 \text { rs. }} \frac{\text { Adjudicación }}{3.600 \text { rs. }} \frac{\%}{720} \frac{\text { Año }}{1862}$

\section{ARAPILES}

$11 \mathrm{Ha}$ y $26 \mathrm{~A}$. (20 tierras).

$1 \mathrm{Ha}$. y $39 \mathrm{~A}$

5 A.

$9 \mathrm{Ha}$.

\begin{tabular}{c} 
Tasacion \\
\hline 18.792 rs. \\
2.250 rs. \\
300 rs. \\
1.500 pts.
\end{tabular}

\begin{tabular}{c} 
Adjudicacion \\
\hline 41.009 rs. \\
7.350 rs. \\
5.110 rs. \\
20.005 pts.
\end{tabular}

\begin{tabular}{c}
$\%$ \\
\hline 217 \\
326 \\
1.703 \\
1.333
\end{tabular}

Año

1859

1869

1869

1874

\section{BARBADILLO}

$57 \mathrm{Ha}$ y 95 A. (560 encinas).

$32 \mathrm{Ha}$ y 76 A. $\ldots . \ldots . \ldots$

$100 \mathrm{Ha}$.

$52 \mathrm{Ha}$.

\begin{tabular}{r} 
Tasacion \\
\hline 5.500 rs. \\
7.312 pts. \\
5.495 pts. \\
10.465 pts.
\end{tabular}

\begin{tabular}{c} 
Adjudicación \\
\hline 14.000 rs. \\
10.020 pts. \\
6.320 pts. \\
30.000 pts.
\end{tabular}

\begin{tabular}{c}
$\%$ \\
\hline 250 \\
137 \\
115 \\
277
\end{tabular}

Año

1860

1870

1870

1870

\section{CABRERIZOS}

\begin{tabular}{|c|c|c|c|c|}
\hline & Tasacion & Adjudicación & $\%$ & Año \\
\hline 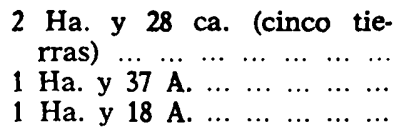 & $\begin{array}{l}3.937 \text { rs. } \\
112 \text { pts. } \\
124 \text { pts. }\end{array}$ & $\begin{array}{l}7.120 \text { rs. } \\
1.030 \text { pts. } \\
124 \text { pts. }\end{array}$ & $\begin{array}{l}180 \\
919 \\
100\end{array}$ & $\begin{array}{l}1859 \\
1877 \\
1878\end{array}$ \\
\hline
\end{tabular}

\section{CALVARRASA DE ABAJO}

$30 \mathrm{Ha}$

Tasacion
22.972 rs.
20.703 pts.

$\frac{\text { Adjudicacion }}{30.000 \mathrm{rs}}$
21.000 pts.

$\frac{96}{134}$

Año

1859

$76 \mathrm{Ha}$

1873

\section{CARBAJOSA DE LA SAGRADA}

$19 \mathrm{Ha}$ y $42 \mathrm{~A}$

\begin{tabular}{c} 
Tasacion \\
\hline 3.450 rs. \\
1.850 rs. \\
150 pts.
\end{tabular}

$\frac{\text { Adjudicación }}{20.200 \text { rs. }}$
6.110 rs.
345 pts.

\begin{tabular}{l}
$\%$ \\
\hline 585 \\
230 \\
230
\end{tabular}

Año 
CASTELLANOS DE MORISCOS

4 A. y $20 \mathrm{ca}$.

$\frac{\text { Tasación }}{1.000 \text { rs. }} \frac{\text { Adjudicación }}{9.000 \text { rs. }} \frac{\%}{900} \frac{\text { Año }}{1862}$

\section{CASTELLANOS DE VILLIQUERA}

14 A. y 53 ca.

$\frac{\text { Tasación }}{680 \mathrm{rs}} \frac{\text { Adjudicación }}{5.100 \mathrm{rs}} \frac{\%}{779} \frac{\text { Año }}{1862}$

\section{CILLEROS EL HONDO}

2 Ha. y 68 A.

7 A. y 54 ca.

12 pedazos de terreno entre 4 A. y 2 Ha. y 30 A. ...

\begin{tabular}{|c|c|c|c|}
\hline Tasacion & Adjudicación & 96 & Año \\
\hline $\begin{array}{l}2.620 \text { rs. } \\
6.750 \text { rs. }\end{array}$ & $\begin{array}{l}15.120 \text { rs. } \\
11.020 \text { rs. }\end{array}$ & $\begin{array}{l}577 \\
163\end{array}$ & $\begin{array}{l}1859 \\
1859\end{array}$ \\
\hline 2.700 rs. & 2.700 rs. & 100 & 1863 \\
\hline
\end{tabular}

\section{DONINOS DE SALAMANCA}

$41 \mathrm{Ha}$. y 47 A. $\ldots . \ldots \ldots$

$26 \mathrm{Ha}$. y 16 A. $\quad \ldots$... $\quad \ldots \ldots$

$12 \mathrm{Ha}$. (tres terrenos) ... ...

8 A. y 38 ca. ... ... ........

\begin{tabular}{c} 
Tasacion \\
\hline 13.600 rs. \\
6.075 rs. \\
5.625 rs. \\
450 rs.
\end{tabular}

\begin{tabular}{c} 
Adjudicación \\
\hline 60.000 rs. \\
34.000 rs. \\
23.010 rs. \\
810 rs.
\end{tabular}

\begin{tabular}{l}
$\%$ \\
\hline 441 \\
559 \\
409 \\
180
\end{tabular}

Año

FLORIDA DE LIEBANA

$100 \mathrm{Ha}$.

\begin{tabular}{l} 
Tasación \\
\hline $67.500 \mathrm{rs}$. \\
$17.000 \mathrm{rs}$.
\end{tabular}

$\frac{\text { Adjudicacion }}{180.000 \text { rs. }}$

$\frac{96}{329}$

\begin{tabular}{l} 
Año \\
\hline 1860 \\
1860
\end{tabular}

FORFOLEDÁ

7 A. y $26 \mathrm{ca}$

$\frac{\text { Tasación }}{850 \text { rs. }} \frac{\text { Adjudicación }}{7.600 \text { rs. }} \frac{\%}{894} \frac{\text { Año }}{1862}$

\section{GALINDO Y PERAHUY}

$36 \mathrm{Ha}$ y $70 \mathrm{~A}$

$75 \mathrm{Ha}$ y $25 \mathrm{~A}$. (varias tie$\begin{array}{lllllll}\text { rras) } & \ldots & \ldots & \ldots & \ldots & \ldots & \ldots\end{array}$

\begin{tabular}{|c|c|c|c|}
\hline Tasación & Adjudicación & $\%$ & Año \\
\hline 6.375 pts. & 10.500 pts. & 164 & 1871 \\
\hline 11.725 pts. & 15.200 pts. & 121 & 1879 \\
\hline
\end{tabular}

\section{GOMECELLO}

$22 \mathrm{~m}$. y $89 \mathrm{~cm}$. (casa) ... ...

\begin{tabular}{|c|c|c|c|}
\hline Tasacion & Adjudicacion & $\%$ & Año \\
\hline $\begin{array}{rr}37,50 & \text { rs. } \\
3.469 & \text { rs. }\end{array}$ & $\begin{array}{l}1.100 \text { rs. } \\
7.005 \text { rs. }\end{array}$ & $\begin{array}{r}2.933 \\
230\end{array}$ & $\begin{array}{l}1862 \\
1873\end{array}$ \\
\hline
\end{tabular}

$7 \mathrm{Ha}$. y $75 \mathrm{~A}$ 3.469 rs. 7.005 rs.

1873 
ANGEL SANCHEZ BLANCO

GUADRAMIRO

19

A. y $56 \mathrm{ca}$

$\frac{\text { Tasación }}{1.260 \mathrm{rs} .} \frac{\text { Adjudicación }}{8.000 \mathrm{rs} .}$

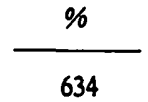

Año

LAS TORRES

\begin{tabular}{|c|c|c|c|c|}
\hline & Tasación & Adjudicación & $\%$ & An̆o \\
\hline tierra) & 4.466 pts. & 10.601 pts. & 237 & 1877 \\
\hline
\end{tabular}

MIRANDA DE AZAN

\begin{tabular}{|c|c|c|c|c|}
\hline & Tasacion & Adjudicacion & $\%$ & Año \\
\hline $\begin{array}{lllllllll}1 & \text { Ha. } & \text { y } & 63 & \text { A. } & \ldots & \ldots & \ldots & \ldots \\
1 & \text { Ha. } & \text { y } & 65 & \text { A. } & \ldots & \ldots & \ldots & \ldots \\
4 & \text { A. } & \text { y } & 47 & \text { ca. } & \ldots & \ldots & \ldots & \ldots\end{array}$ & $\begin{array}{l}2.500 \text { rs. } \\
3.600 \text { rs. } \\
1.560 \text { rs. }\end{array}$ & $\begin{array}{l}14.120 \text { rs. } \\
18.100 \text { rs. } \\
4.510 \text { rs. }\end{array}$ & $\begin{array}{l}564 \\
500 \\
289\end{array}$ & $\begin{array}{l}1863 \\
1863 \\
1863\end{array}$ \\
\hline
\end{tabular}

MONTERRUBIO DE LA ARMUNA

4 A. y 13 ca. $\ldots \ldots \ldots \ldots \ldots$ 10 tierras, desde 19 A. a $1 \mathrm{Ha}$. y 21 A. ... ... ... 4 A. y $20 \mathrm{ca}$.

\begin{tabular}{l} 
Tasacion \\
\hline $600 \mathrm{rs}$. \\
$3.500 \mathrm{rs}$. \\
$1.000 \mathrm{rs}$.
\end{tabular}

$\frac{\text { Adjudicacion }}{675 \mathrm{rs} .}$
$6.030 \mathrm{rs}$.
$3.550 \mathrm{rs}$.

$\% 6$
112
169
335

\begin{tabular}{l} 
Año \\
\hline 1864 \\
1859 \\
1862
\end{tabular}

\section{MOZARBEZ}

6 Ha. y 68 A. (13 tierras).

$7 \mathrm{Ha}$ y 39 A. (15 tierras).

$5 \mathrm{Ha}$ y 99 A. (17 tierras).

$9 \mathrm{Ha}$ y 44 A. (20 tierras).

$7 \mathrm{Ha}$ y $11 \mathrm{~A}$. (15 tierras).

$6 \mathrm{Ha}$ y $5 \mathrm{~A}$. (16 tierras).

$5 \mathrm{Ha}$ y $80 \mathrm{~A}$. (18 tierras).

$5 \mathrm{Ha}$ y. 75 A. (16 tierras).

$6 \mathrm{Ha}$ y 83 A. (18 tierras).

$5 \mathrm{Ha}$ y 51 A. (15 tierras).

$5 \mathrm{Ha}$ y 85 A. (14 tierras).

5 Ha. y 89 A. (16 tierras).

$5 \mathrm{Ha}$ y 89 A. (16 tierras).

$8 \mathrm{Ha}$ y 8 A. (10 tierras).

3 A. y 20 ca. (alameda) ...

$1 \mathrm{Ha}$ y $39 \mathrm{ca}$. (una tierra).

$55 \mathrm{Ha}$ y $64 \mathrm{~A}$. (cinco tie-

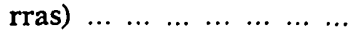

$70 \mathrm{Ha}$ y 33 A. (cinco tierras)

\begin{tabular}{|c|c|c|c|}
\hline Tasacion & Adjudicación & $\%$ & $A \bar{n} o$ \\
\hline $\begin{array}{c}7.796 \text { rs. } \\
8.235 \text { rs. } \\
6.574 \text { rs. } \\
9.035 \text { rs. } \\
6.468 \text { rs. } \\
6.657 \text { rs. } \\
6.401 \text { rs. } \\
6.401 \text { rs. } \\
6.220 \text { rs. } \\
5.467 \text { rs. } \\
6.120 \text { rs. } \\
6.367 \text { rs. } \\
7.078 \text { rs. } \\
10.423 \text { rs. } \\
2.812 \text { rs. } \\
2.250 \text { rs. }\end{array}$ & $\begin{array}{r}7.796 \text { rs. } \\
8.235 \text { rs. } \\
25.120 \text { rs. } \\
40.100 \text { rs. } \\
24.310 \text { rs. } \\
22.020 \text { rs. } \\
20.130 \text { rs. } \\
23.000 \text { rs. } \\
7.020 \text { rs. } \\
20.120 \text { rs. } \\
23.010 \text { rs. } \\
22.040 \text { rs. } \\
29.130 \text { rs. } \\
33.000 \text { rs. } \\
2.820 \text { rs. } \\
7.350 \text { rs. }\end{array}$ & $\begin{array}{l}100 \\
100 \\
382 \\
443 \\
375 \\
333 \\
314 \\
359 \\
112 \\
368 \\
375 \\
346 \\
411 \\
316 \\
100,27 \\
326\end{array}$ & $\begin{array}{l}1859 \\
1859 \\
1859 \\
1859 \\
1859 \\
1859 \\
1859 \\
1859 \\
1859 \\
1859 \\
1859 \\
1859 \\
1859 \\
1859 \\
1859 \\
1859\end{array}$ \\
\hline 4.075 rs. & 6.920 rs. & 169 & 1870 \\
\hline 6.590 rs. & 6.600 rs. & 100,15 & 1870 \\
\hline
\end{tabular}


INCIDENCIA LEGISLACION DESAMORTIZADORA SOBRE MUNICIPIOS DEL P. J. DE SALAMANCA

MOZODIEL DE SACHINIGO

$5 \mathrm{Ha}$ y 11 A. (nueve tie-

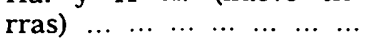

9 Ha. y 5 A.

\begin{tabular}{|c|c|c|c|}
\hline Tasacion & Adjudicación & $\%$ & $A \bar{n} O$ \\
\hline $\begin{array}{l}4.000 \text { rs. } \\
6.200 \text { rs. }\end{array}$ & $\begin{array}{l}17.710 \text { rs. } \\
76.100 \text { rs. }\end{array}$ & $\begin{array}{r}442 \\
1.227\end{array}$ & $\begin{array}{l}1862 \\
1862\end{array}$ \\
\hline
\end{tabular}

PAJARES DE LA LAGUNA

18 tierras (las mayores, 20 Ha., 6 Ha. y 4 Ha.).

$\frac{\text { Tasación }}{4.500 \text { pts. }} \frac{\text { Adjudicación }}{28.100 \text { pts. }} \frac{\%}{615} \frac{\text { Año }}{}$

PALENCIA DE NEGRILLA

2 Ha. y 35 A.

$\frac{\text { Tasacion }}{1.136 \text { pts. }}$

$\frac{\text { Adjudicación }}{1.500 \text { pts. }}$

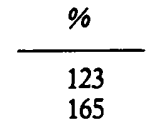

Año

1.626 pts.

1877

1877

PARADA DE ARRIBA

$20 \mathrm{Ha}$. y 6 A. $\ldots \ldots \ldots \ldots$

\begin{tabular}{|c|c|c|c|}
\hline Tasacion & Adjudicación & $\%$ & $A \tilde{n} o$ \\
\hline $18.650 \mathrm{r}$ & 60.510 rs. & 324 & 1862 \\
\hline 17.820 rs. & 71.010 rs. & 398 & 1862 \\
\hline 500 rs. & $2.040 \mathrm{rs}$. & 408 & 1862 \\
\hline
\end{tabular}

8 A. y 4 ca.

$500 \mathrm{rs}$

$2.040 \mathrm{rs}$.

PARADA DE RUBIALES

$2 \mathrm{Ha}$ y 18 A. (cinco tie$\begin{array}{lllllll}\text { rras) } & \ldots & \ldots & \ldots & \ldots & \ldots & \ldots\end{array}$

$12 \mathrm{Ha}$. y $7 \mathrm{~A}$. (nueve tie-

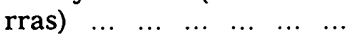

17 A. y 88 ca. (alameda).

$40 \mathrm{Ha}$ y $42 \mathrm{~A}$. (dos tierras).

$146 \mathrm{Ha}$. y $23 \mathrm{~A}$. (cuatro tierras) $\quad \ldots \ldots \ldots c c c c c$

$178 \mathrm{Ha}$ y $87 \mathrm{~A}$. (cuatro tie-

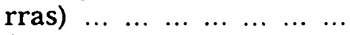

68 A. y 76 ca.

Tasacion

\subsection{0 rs.}

$5.500 \mathrm{rs}$.

$4.500 \mathrm{rs}$.

15.090 rs.

41.212 rs.

41.400 rs.

101 escs.
Adjudicación

$5.160 \mathrm{rs}$.

55.000 rs.

10.160 rs.

100.000 rs.

55.010 rs.

90.030 rs.

117 escs.

\begin{tabular}{rrrr}
\multicolumn{1}{l}{$\%$} & & Año \\
\cline { 1 - 1 } 120 & & 1860 \\
& & \\
1.000 & & 1861 \\
225 & & 1860 \\
669 & & 1861 \\
& & \\
133 & & 1861 \\
222 & & 1861 \\
115 & & 1867
\end{tabular}

\section{PELABRAVO}

36 Ha. y 29 A. $\ldots . \ldots . \ldots$.

$14 \mathrm{Ha}$. y 93 A. $\ldots . \ldots . \ldots$.

3 A. y 13 ca. (alameda) ...

\begin{tabular}{|c|c|c|c|}
\hline Tasación & Adjudicación & $\%$ & $A \tilde{n} o$ \\
\hline $\begin{array}{r}17.270 \text { rs. } \\
6.710 \text { rs. } \\
1.500 \text { rs. } \\
26.503 \text { pts. }\end{array}$ & $\begin{array}{r}54.010 \text { rs. } \\
16.610 \text { rs. } \\
4.220 \text { rs. } \\
37.500 \text { pts. }\end{array}$ & $\begin{array}{l}312 \\
341 \\
281 \\
141\end{array}$ & $\begin{array}{l}1859 \\
1859 \\
1865 \\
1881\end{array}$ \\
\hline
\end{tabular}


SAN CRISTOBAL DE LA CUESTA

34 Ha. y 77 A.

$\frac{\text { Tasación }}{4.692 \text { pts. }} \frac{\text { Adjudicación }}{4.692 \text { pts. }} \frac{. \%}{100} \frac{\text { Año }}{1874}$

SAN PEDRO DE ROZADOS

10 Ha. y 41 A.

$17 \mathrm{Ha}$ y $60 \mathrm{~A}$. (siete tierras) $\quad \ldots \quad \ldots \quad \ldots \quad \ldots \quad \ldots \quad \ldots$

$24 \mathrm{Ha}$. y 28 A. (cuatro tierras) $\quad \ldots \quad \ldots \quad \ldots \quad \ldots \quad \ldots \quad \ldots$

$8 \mathrm{Ha}$. y $72 \mathrm{~A}$. (cinco tierras)

\section{SANTA MARTA}

17 A. y 16 ca.

\section{TEJARES}

$6 \mathrm{Ha}$ y $61 \mathrm{~A}$. (cuatro tierras) $\ldots \ldots \ldots c c c c c c$

86 A. y 75 ca. (alameda). 34 A. y 21 ca. (alameda).

TOPAS

10 A. y 96 ca.

$\frac{\text { Tasacion }}{1.000 \mathrm{rs}}$

\begin{tabular}{|c|c|c|c|}
\hline Tasacion & Adjudicación & $\%$ & $A \tilde{n} o$ \\
\hline $6.651 \mathrm{rs}$. & $21.120 \mathrm{rs}$. & 316 & 1859 \\
\hline $16.087 \mathrm{rs}$. & 34.010 rs. & 210 & 1860 \\
\hline 2.790 pts. & 5.015 pts. & 179 & 1872 \\
\hline 1.100 pts. & 8.000 pts. & 727 & 1875 \\
\hline
\end{tabular}

$\frac{\text { Tasación }}{1.035 \text { rs. }} \frac{\text { Adjudicación }}{4.500 \mathrm{rs} .} \frac{\%}{434} \frac{\text { Año }}{1861}$

\section{TORRESMENUDAS}

3 A. y 13 ca

$\begin{array}{llllllll}7 & \mathrm{Ha} . \text { y } & 41 & \text { A. } & \ldots & \ldots & \ldots & \ldots\end{array}$

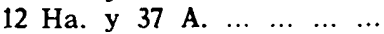

$13 \mathrm{Ha}$. y 63 A. $\ldots . \ldots . . . .$.

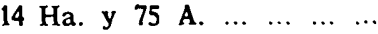

$5 \mathrm{Ha}$ y $36 \mathrm{~A}$.

\begin{tabular}{|c|c|c|c|}
\hline Tasación & Adjudicación & $\%$ & Año \\
\hline $\begin{array}{r}5.490 \mathrm{rs} . \\
380 \mathrm{rs} . \\
151 \mathrm{rs} .\end{array}$ & $\begin{array}{r}22.100 \text { rs. } \\
8.030 \text { rs. } \\
730 \text { rs. }\end{array}$ & $\begin{array}{r}402 \\
2.113 \\
483\end{array}$ & $\begin{array}{l}1861 \\
1865 \\
1880\end{array}$ \\
\hline
\end{tabular}

\section{VALVERDON}

$31 \mathrm{Ha}$ y $54 \mathrm{~A}$

48 A. y 74 ca.

\begin{tabular}{|c|c|c|c|}
\hline Tasacion & Adjudicación & $\%$ & Año \\
\hline $3.534 \mathrm{rs}$ & $7.000 \mathrm{rs}$. & 169 & 1860 \\
\hline $2.691 \mathrm{rs}$ & $6.000 \mathrm{rs}$. & 222 & 1860 \\
\hline 3.859 rs. & $6.000 \mathrm{rs}$. & 158 & 1860 \\
\hline $4.469 \mathrm{rs}$. & 10.000 rs. & 200 & 1860 \\
\hline $4.496 \mathrm{rs}$. & 14.000 rs. & 311 & 1860 \\
\hline 5.400 rs. & 14.010 rs. & 259 & 1860 \\
\hline
\end{tabular}

\begin{tabular}{|c|c|c|c|}
\hline Tasación & Adjudicación & $\%$ & Año \\
\hline $\begin{array}{l}9.350 \text { rs. } \\
2.600 \text { rs. }\end{array}$ & $\begin{array}{r}35.010 \text { rs. } \\
7.600 \text { rs. }\end{array}$ & $\begin{array}{l}374 \\
293\end{array}$ & $\begin{array}{l}1862 \\
1861\end{array}$ \\
\hline
\end{tabular}


INCIDENCIA LEGISLACION DESAMORTIZADORA SOBRE MUNICIPIOS DEL P. J. DE SALAMANCA 101 LAS VEGUILLAS

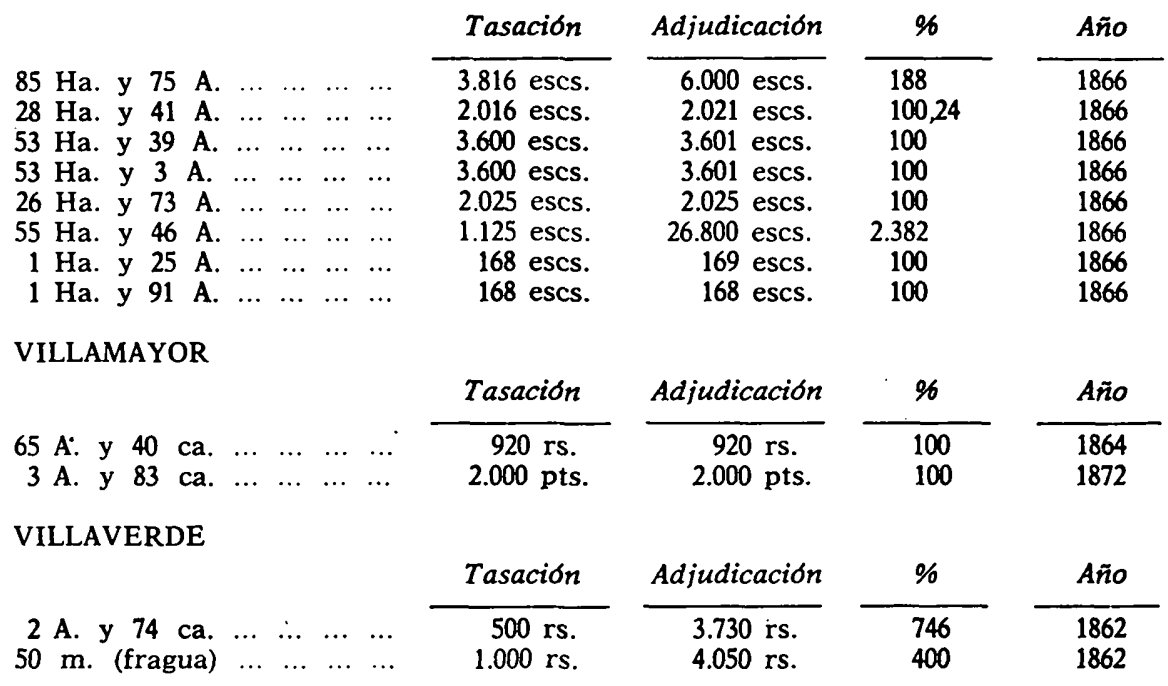

AYUNTAMIENTO DE SALAMANCA. PROPIEDADES RUSTICAS

1 Ha. y 6 A. (tres tierras), próximas a casco urbano. Vega y Huérfanos.... ...

$1 \mathrm{Ha}$. y 2 A. en Mozodiel de $\begin{array}{llllll}\text { Sachinigo } & \ldots & \ldots & \ldots & \ldots & \ldots\end{array}$

1 Ha. y 65 A. en San Cristobal de la Cuesta ... ... ...

35 A. y 33 ca. La mancebía e arrabal del puente ... ...

$1 / 4$ proindiviso de $543 \mathrm{Ha}$. y $37 \mathrm{~A}$. de la Dehesa de Valverde de Valmuza ... 1/5 proindiviso de $844 \mathrm{Ha}$. y 54 A. en Cardeñosa (To-

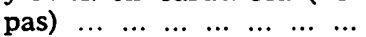

$5 \mathrm{Ha}$ y 17 A. (cinco tierras).

5 Ha. y 88 A. (siete tierras en Gomecello) (Velasco

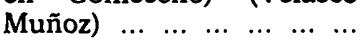

$5 \mathrm{Ha}$ y 84 A. (cinco tierras en Arcediano) ... $\ldots \ldots \ldots$

2 Ha. y 15 A. (tres tierras en Palencia de Negrilla).

5 Ha. y 28 A. (13 tierras en Castellanos de Moriscos).

$6 \mathrm{Ha}$. y $12 \mathrm{~A}$. (siete tierras en Carrascal de Barregas). $336 \mathrm{Ha}$. y 64 A., "El Marín», en término municipal de Salamanca, dividido en 10 porciones $\ldots \ldots \ldots \ldots \ldots$

\begin{tabular}{|c|c|c|c|}
\hline Tasacion & Adjudicación & $\%$ & $A \tilde{n} o$ \\
\hline $25.000 \mathrm{rs}$ & 41.800 rs. & 165 & 1860 \\
\hline 1.734 rs. & 4.010 rs. & 225 & 1860 \\
\hline $2.118 \mathrm{rs}$. & 3.560 rs. & 168 & 1860 \\
\hline 3.125 rs. & 8.000 rs. & 255 & 1860 \\
\hline 66.999 rs. & 212.010 rs. & 316 & 1860 \\
\hline $\begin{array}{l}62.500 \mathrm{rs} . \\
16.250 \mathrm{rs} .\end{array}$ & $\begin{array}{r}400.000 \text { rs. } \\
20.100 \text { rs. }\end{array}$ & $\begin{array}{l}640 \\
123\end{array}$ & $\begin{array}{l}1860 \\
1860\end{array}$ \\
\hline 3.848 rs. & 10.010 rs. & 260 & 1861 \\
\hline 8.250 rs. & 9.410 rs. & 114 & 1861 \\
\hline 6.000 rs. & 18.020 rs. & 300 & 1861 \\
\hline 9.000 rs. & $25.070 \mathrm{rs}$ & 277 & 1861 \\
\hline $9.000 \mathrm{rs}$. & 29.020 rs. & 322 & 1862 \\
\hline 633.593 rs. & 1.369 .540 rs. & 216 & 1861 \\
\hline
\end{tabular}


AYUNTAMIENTO DE SALAMANCA. PROPIEDADES URBANAS

\begin{tabular}{|c|c|c|c|c|}
\hline & Tasación & Adjudicación & $\%$ & Año \\
\hline $\begin{array}{rlllllll}11 \mathrm{~m}^{2} & (\text { portal } & \text { calle } & \text { de } & \text { la } \\
\text { Rúa }) & \ldots & \ldots & \ldots & \ldots & \ldots & \ldots & \ldots\end{array}$ & 550 rs. & $15.000 \mathrm{rs}$ & 2.727 & 1859 \\
\hline $4.270 \mathrm{~m}^{2}$ (El Calvario) ... . . & $15.680 \mathrm{rs}$. & 33.160 rs. & 211 & 1860 \\
\hline $\begin{array}{l}66,76 \mathrm{~m}^{2} \text { (cuadra en la pa- } \\
\text { rroquia de Santiago). } 1 .^{\circ} \\
\text { subasta, } 2.300 \text { rs. No pos- } \\
\text { tor. 2." subasta ... ... ... }\end{array}$ & 360 rs. & 700 rs. & 194 & 1860 \\
\hline $\begin{array}{c}41 \mathrm{~m}^{2} \text { (solar Monte Olivete). } \\
10^{*} \text { y } 20^{*} \text { subasta, } 2.020 \mathrm{rs} . \\
\text { No postor, } 30^{*} \text { subasta }\end{array}$ & 120 rs. & $710 \mathrm{rs}$. & 591 & 1861 \\
\hline 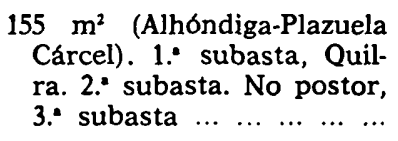 & 18.666 rs. & $45.010 \mathrm{rs}$. & 241 & 1860 \\
\hline 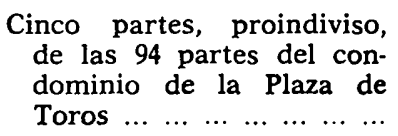 & $5.250 \mathrm{rs}$ & 5.250 rs. & 100 & 1862 \\
\hline
\end{tabular}

\section{APÉNDICE NƯMERO 2}

Relación nominal de adjudicatarios, con individualización de los Municipios en que radican las propiedades adjudicadas y concreción del Municipio residencia de los adjudicatarios. 


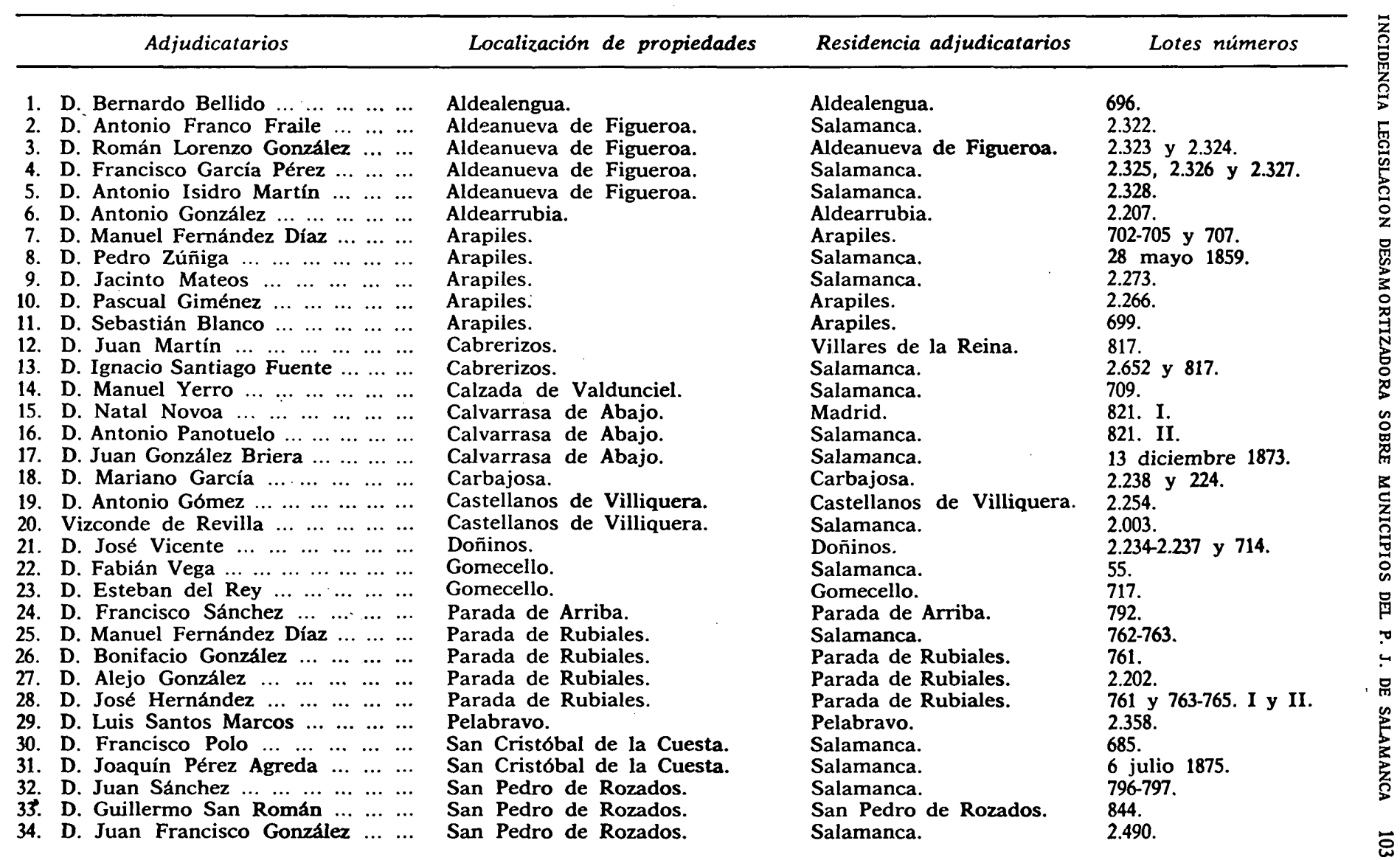




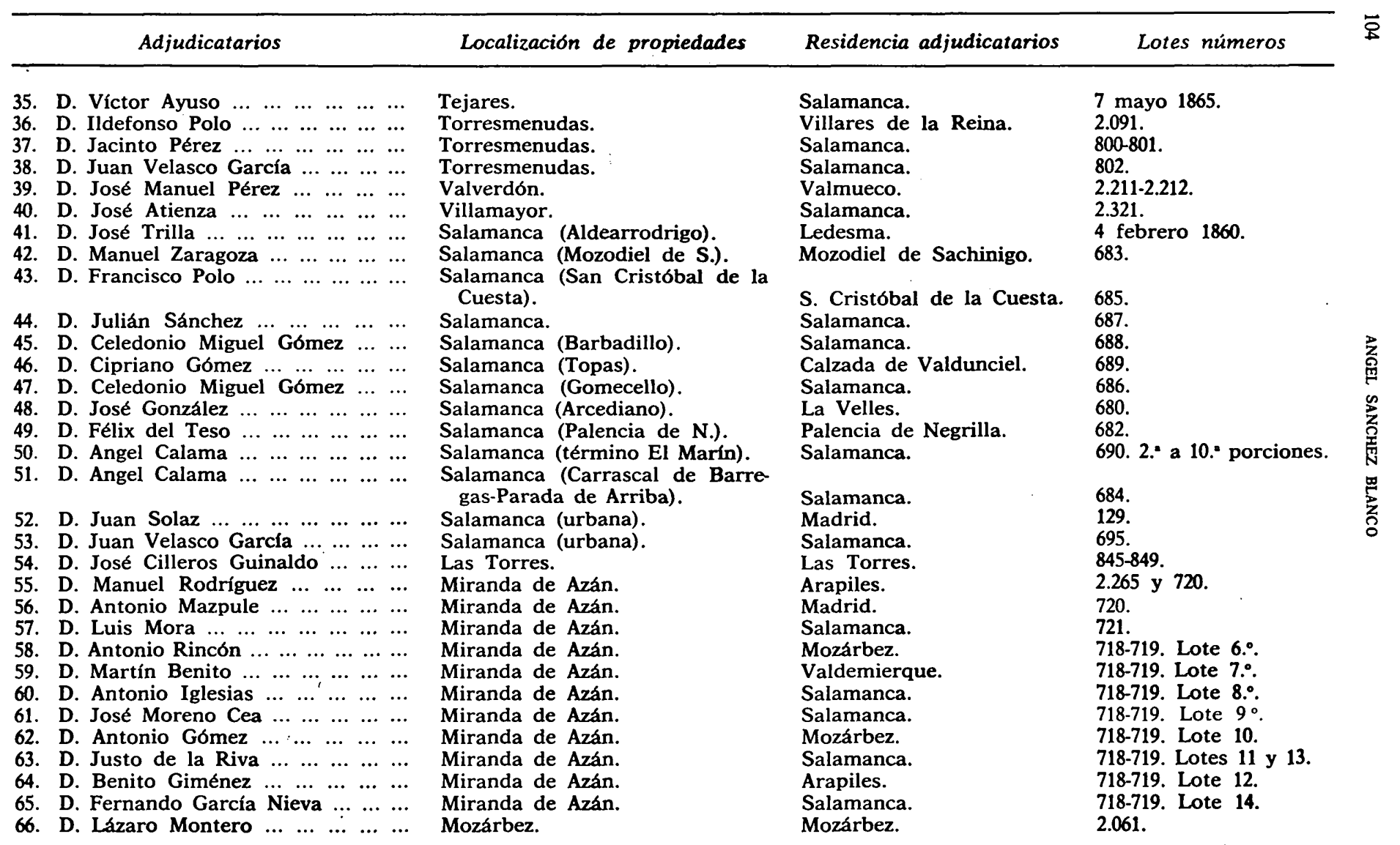




\begin{tabular}{|c|c|c|c|c|}
\hline & Adjudicatarios & Localización de propiedades & Residencia adjudicatarios & Lotes números \\
\hline $\begin{array}{l}67 . \\
68 . \\
69 . \\
70 . \\
71 . \\
72 . \\
73 . \\
74 . \\
75 . \\
76 . \\
77 . \\
78 .\end{array}$ & 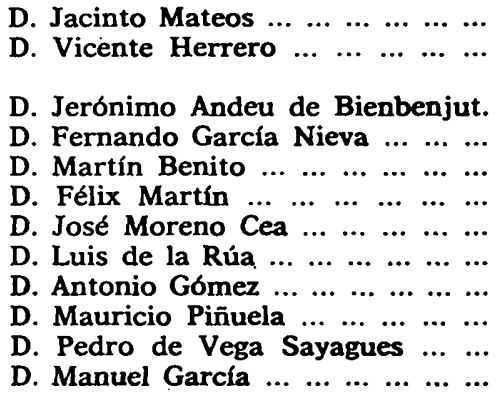 & $\begin{array}{l}\text { Mozárbez. } \\
\text { Monterrubio de la Armuña. } \\
\text { Moriscos. } \\
\text { Mozárbez. } \\
\text { Mozárbez. } \\
\text { Mozárbez. } \\
\text { Mozárbez. } \\
\text { Mozodiel de Sachinigo. } \\
\text { Mozodiel de Sachinigo. } \\
\text { Palencia de Negrilla. } \\
\text { Palencia de Negrilla. } \\
\text { Parada de Arriba. }\end{array}$ & $\begin{array}{l}\text { Salamanca. } \\
\text { Monterrubio de la Ar- } \\
\text { muña. } \\
\text { Salamanca. } \\
\text { Salamanca. } \\
\text { Valdemierque. } \\
\text { Mozárbez. } \\
\text { Salamanca. } \\
\text { Salamanca. } \\
\text { Castellanos de Villiquera. } \\
\text { Salamanca. } \\
\text { Palencia de Negrilla. } \\
\text { Salamanca. }\end{array}$ & $\begin{array}{l}2.273 . \\
2.310 . \\
841 . \\
725-760 \text {. Lotes } 1 .^{\circ} \text { y } 3 .^{\circ} \\
725-760 . \text { Lote } 2 .^{\circ} \\
725-760 \text {. Lote } 4 .^{\circ} \\
725-760 . \text { Lote } 5 .^{\circ} \\
826 . \text { I. } \\
826 . \text { II. } \\
2.504 . \\
824 . \\
792-793 .\end{array}$ \\
\hline
\end{tabular}




\section{APÉNDICE NƯMERO 3}

Relación de Municipios afectados por la desamortización, con concreción de las superficies calificadas como bienes de propios y superficies calificadas como bienes comunales, determinación de la superficie total desamortizada y de la superficie total del término municipal, con expresión de la relación porcentual entre ambas.

\section{ALDEALENGUA}

$\begin{array}{lcc}\text { Propios } & \text { Comunales } & \text { Total } \\ 18 \mathrm{Ha} . & - & 18 \mathrm{Ha} \\ 13 \mathrm{~A} . & 16 \mathrm{~A} . & 30 \mathrm{~A} . \\ 79 \mathrm{ca} . & 32 \mathrm{ca} . & 11 \mathrm{ca} .\end{array}$

Superficie término municipal

Porcentaje superficie desamortizada en relación con superficie total del término municipal

2. ALDEANUEVA DE FIGUEROA

\section{Propios}

$344 \mathrm{Ha}$.

$92 \mathrm{~A}$.

$87 \mathrm{ca}$.

\section{Comunales}

$100 \mathrm{Ha}$.

$78 \mathrm{~A}$.

13 ca.
Total

$445 \mathrm{Ha}$.

$71 \mathrm{~A}$.

(más aprovechamiento de 557 encinas)

Superficie término municipal

$5.512 \mathrm{Ha}$.

Porcentaje superficie desamortizada en relación con superficie

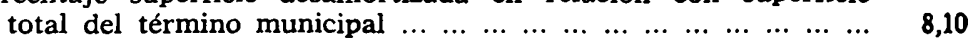

3. ALDEARRUBIA

Propios

55 A.

35 ca.

$\begin{array}{llllllllllllll}\text { Superficie término municipal } & \ldots & \ldots & \ldots & \ldots & \ldots & \ldots & \ldots & \ldots & \ldots & \ldots & \ldots & \ldots & 3.247 \\ \mathbf{~ H a}\end{array}$

$\begin{array}{lllllllllllllllllllll}\text { Porcentaje } & \ldots & \ldots & \ldots & \ldots & \ldots & \ldots & \ldots & \ldots & \ldots & \ldots & \ldots & \ldots & \ldots & \ldots & \ldots & \ldots & \ldots & \ldots & \ldots & \ldots\end{array}$

4. ALDEATEJADA

Propios

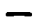

\section{Comunales}

$4 \mathrm{~A}$.

$95 \mathrm{ca}$.

Superficie término municipal 
5. ALDEASECA

$$
\begin{aligned}
& \text { Propios } \\
& 3 \mathrm{Ha} . \\
& 77 \mathrm{~A} . \\
& 8 \mathrm{ca} .
\end{aligned}
$$

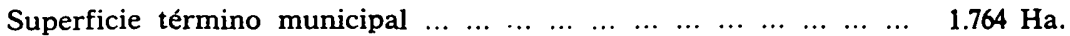

$\begin{array}{lllllllllllllllllllll}\text { Porcentaje } & \ldots & \ldots & \ldots & \ldots & \ldots & \ldots & \ldots & \ldots & \ldots & \ldots & \ldots & \ldots & \ldots & \ldots & \ldots & \ldots & \ldots & \ldots & \ldots & 0,10\end{array}$

6. ARAPILES

$\begin{array}{lrr}\text { Propios } & \text { Comunales } & \text { Total } \\ 14 \mathrm{Ha} . & 9 \mathrm{Ha} . & 23 \mathrm{Ha} . \\ 65 \mathrm{~A} . & 6 \mathrm{~A} . & 72 \mathrm{~A} . \\ 67 \mathrm{ca} . & 56 \mathrm{ca} . & 23 \mathrm{ca} .\end{array}$

$\begin{array}{lllllllllllllll}\text { Superficie término municipal } & \ldots & \ldots & \ldots & \ldots & \ldots & \ldots & \ldots & \ldots & \ldots & \ldots & \ldots & \ldots & 1.577 \mathrm{Ha} .\end{array}$

$\begin{array}{lllllllllllllllllllllll}\text { Porcentaje } & \ldots & \ldots & \ldots & \ldots & \ldots & \ldots & \ldots & \ldots & \ldots & \ldots & \ldots & \ldots & \ldots & \ldots & \ldots & \ldots & \ldots & \ldots & \ldots & 1,03\end{array}$

7. ARCEDIANO

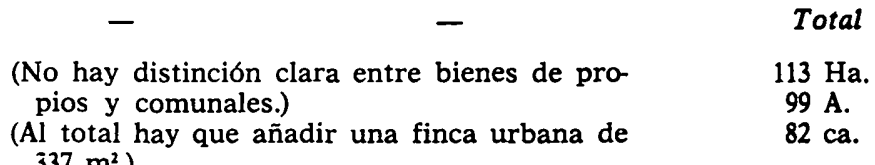
$337 \mathrm{~m}^{2}$.)

Superficie término municipal

Porcentaje

82 ca.

99 A.

82 ca.

$1.110 \mathrm{Ha}$. 10

8. BARBADILLO

$\begin{array}{ccc}\text { Propios } & \text { Comunales } & \text { Total } \\ - & 177 \mathrm{Ha} . & - \\ 55 \mathrm{~A} . & \text { (Hay que añadir apro- } \\ 27 \mathrm{ca} . & \text { vechamiento comunal } \\ & & \text { de } 560 \text { encinas) }\end{array}$

$\begin{array}{llllllllllllllll}\text { Superficie término municipal } & \ldots & \ldots & \ldots & \ldots & \ldots & \ldots & \ldots & \ldots & \ldots & \ldots & \ldots & \ldots & 1.663 & \mathrm{Ha} .\end{array}$

$\begin{array}{llllllllllllllllllllll}\text { Porcentaje } & \ldots & \ldots & \ldots & \ldots & \ldots & \ldots & \ldots & \ldots & \ldots & \ldots & \ldots & \ldots & \ldots & \ldots & \ldots & \ldots & \ldots & \ldots & \ldots & & \\ 7\end{array}$

9. CABRERIZOS

$\begin{array}{ccc}\text { Propios } & \text { Comunales } & \text { Total } \\ 3 \mathrm{Ha} & 2 \mathrm{Ha} & 6 \mathrm{Ha} . \\ 49 \mathrm{~A} . & 55 \mathrm{~A} . & 5 \mathrm{~A} . \\ 41 \mathrm{ca} . & 89 \mathrm{ca} . & 30 \mathrm{ca} .\end{array}$

$\begin{array}{llllllllllllll}\text { Superficie término municipal } & \ldots & \ldots & \ldots & \ldots & \ldots & \ldots & \ldots & \ldots & \ldots & \ldots & \ldots & \ldots & 1.241 \mathrm{Ha}\end{array}$

$\begin{array}{llllllllllllllllllllll}\text { Porcentaje } & \ldots & \ldots & \ldots & \ldots & \ldots & \ldots & \ldots & \ldots & \ldots & \ldots & \ldots & \ldots & \ldots & \ldots & \ldots & \ldots & \ldots & \ldots & \ldots & 0,45\end{array}$ 
10. CALZADA DE VALDUNCIEL

$\begin{array}{lcc}\text { Propios } & \text { Comunales } & \text { Total } \\ 8 \mathrm{Ha} . & - & - \\ 64 \mathrm{~A} . & \text { (Hay que añadir a los bienes de propios una } \\ 59 \mathrm{ca} . & \text { finca urbana de } 458 \mathrm{~m}^{2} \text {.) }\end{array}$

Superficie término municipal $2.007 \mathrm{Ha}$. Porcentaje

11. CALVARRASA DE ABAJO

$\begin{array}{lcr}\text { Propios } & \text { Comunales } & \text { Total } \\ & & \\ 68 \mathrm{Ha} & 176 \mathrm{Ha} & 245 \mathrm{Ha} . \\ 82 \mathrm{~A} . & 36 \mathrm{~A} . & 16 \mathrm{~A} . \\ 23 \mathrm{ca} . & 78 \mathrm{ca} . & 1 \mathrm{ca} .\end{array}$

Superficie término municipal

$2.833 \mathrm{Ha}$.

Porcentaje

\section{...}

$78 \mathrm{ca}$.

12. CALVARRASA DE ARRIBA

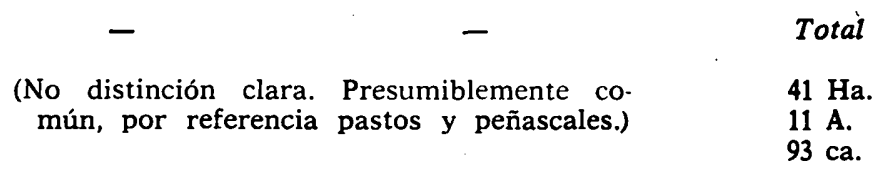

Superficie término municipal

$2.550 \mathrm{Ha}$.

Porcentaje

$\begin{array}{lllllllllllll} & \ldots & \ldots & \ldots & \ldots & \ldots & \ldots & \ldots & \ldots & \ldots & \ldots & \ldots & \ldots\end{array}$

13. CARBAJOSA DE LA SAGRADA

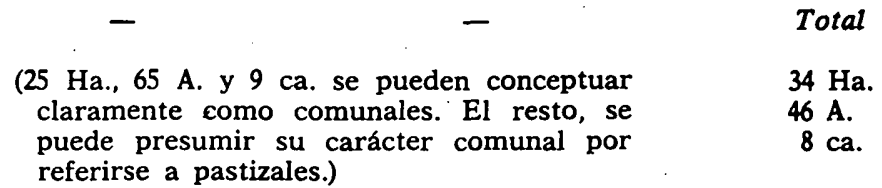

$\begin{array}{llllllllllllll}\text { Superficie término municipal } & \ldots & \ldots & \ldots & \ldots & \ldots & \ldots & \ldots & \ldots & \ldots & \ldots & \ldots & \ldots & 1.335 \\ \mathrm{Ha}\end{array}$

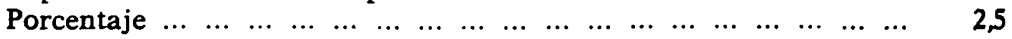

14. CARRASCAL DE BARREGAS

$$
\begin{gathered}
\text { Comunales } \\
\begin{array}{c}
2 \mathrm{Ha} . \\
70 \mathrm{~A} . \\
75 \mathrm{ca} .
\end{array}
\end{gathered}
$$

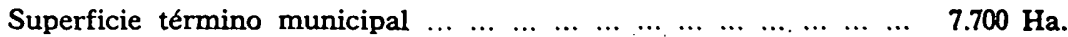

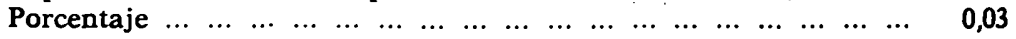


15. CARRASCAL DEL OBISPO

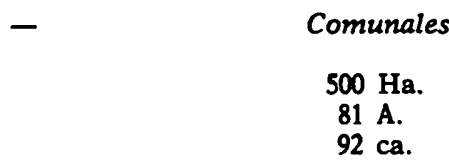

Superficie término municipal . $4.099 \mathrm{Ha}$. Porcentaje

$92 \mathrm{ca}$.

16. CILLEROS EL HONDO

$\begin{array}{lcc}\text { Propios } & \text { Comunales } & \text { Total } \\ 65 \mathrm{Ha} . & 8 \mathrm{Ha} & 74 \mathrm{Ha} . \\ 53 \mathrm{~A} . & 88 \mathrm{~A} . & 13 \mathrm{~A} . \\ 19 \mathrm{ca} . & 4 \mathrm{ca} . & 79 \mathrm{ca} .\end{array}$

$\begin{array}{llllllllllllll}\text { Superficie término municipal } & \ldots & \ldots & \ldots & \ldots & \ldots & \ldots & \ldots & \ldots & \ldots & \ldots & \ldots & \ldots & 1.442 \\ \mathrm{Ha}\end{array}$ $\begin{array}{lllllllllllllllllllll}\text { Porcentaje } & \ldots & \ldots & \ldots & \ldots & \ldots & \ldots & \ldots & \ldots & \ldots & \ldots & \ldots & \ldots & \ldots & \ldots & \ldots & \ldots & \ldots & \ldots & & 3,5\end{array}$

* 62 Ha. limitadas a derecho de vuelo, BVBN, núm. 713.

17. CASTELlaNOS DE MORISCOS

\section{Comunales}

4 A.

$20 \mathrm{ca}$.

Superficie término municipal

Porcentaje

18. CASTELLANOS DE VILLIQUERA

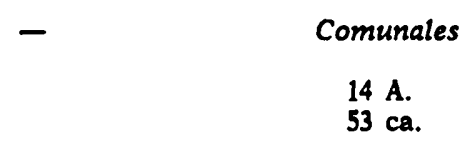

Superficie término municipal

Porcentaje

19. DONINOS DE SALAMANCA

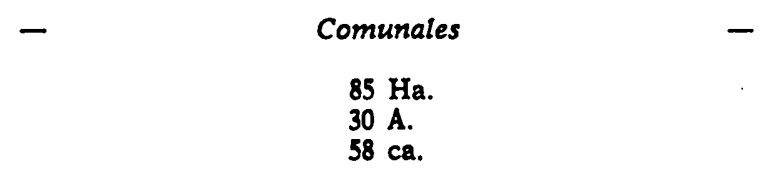

Superficie término municipal

$1.402 \mathrm{Ha}$.

Porcentaje 
20. ESPINO DE LA ORBADA

$$
\begin{aligned}
& \text { Comunales } \\
& 42 \mathrm{~m} . \\
& 91 \mathrm{cms} \\
& \text { (casa fragua) }
\end{aligned}
$$

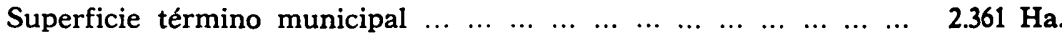

$\begin{array}{llllllllllllllllllllll}\text { Porcentaje } & \ldots & \ldots & \ldots & \ldots & \ldots & \ldots & \ldots & \ldots & \ldots & \ldots & \ldots & \ldots & \ldots & \ldots & \ldots & \ldots & \ldots & \ldots & 0,002\end{array}$

\section{FLORIDA DE LIEBANA}

\section{Comunales \\ $146 \mathrm{Ha}$. \\ $97 \mathrm{~A}$. \\ $27 \mathrm{ca}$.}

Superficie término municipal

22. FORFOLEDA

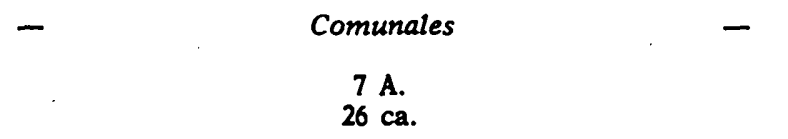

$\begin{array}{lllllllllllllll}\text { Superficie término municipal } & \ldots & \ldots & \ldots & \ldots & \ldots & \ldots & \ldots & \ldots & \ldots & \ldots & \ldots & . & 3.788 \mathrm{Ha} .\end{array}$

$\begin{array}{llllllllllllllllllllll}\text { Porcentaje } & \ldots & \ldots & \ldots & \ldots & \ldots & \ldots & \ldots & \ldots & \ldots & \ldots & \ldots & \ldots & \ldots & \ldots & \ldots & \ldots & \ldots & \ldots & \ldots & 0,02\end{array}$

23. GALINDO Y PERAHUY

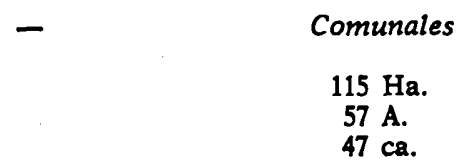

Superficie término municipal

4.405 Ha.

Porcentaje

24. GOMECELLO

$\begin{array}{cc}\text { Propios } & \text { Comunales } \\ 22 \mathrm{~m} . & 7 \mathrm{Ha} . \\ 89 \mathrm{~cm} . & 75 \mathrm{~A} . \\ & 52 \mathrm{ca} .\end{array}$

Superficie término municipal

$2.066 \mathrm{Ha}$.

Porcentaje 


\section{LA VELLES}

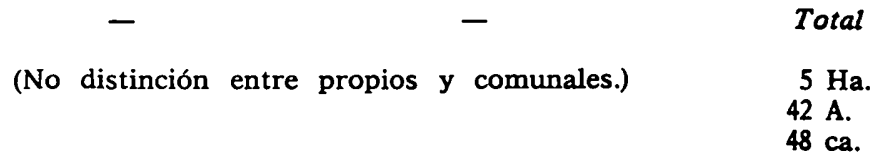

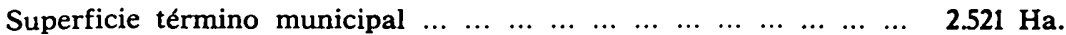

$\begin{array}{llllllllllllllllllllll}\text { Porcentaje } & \ldots & \ldots & \ldots & \ldots & \ldots & \ldots & \ldots & \ldots & \ldots & \ldots & \ldots & \ldots & \ldots & \ldots & \ldots & \ldots & \ldots & \ldots & \ldots & 0,2\end{array}$

26. LAS TORRES

Comunales
$14 \mathrm{Ha}$.
$94 \mathrm{~A}$.
$93 \mathrm{ca}$.

Superficie término municipal

$971 \mathrm{Ha}$.

Porcentaje

27. MIRANDA DE AZAN

Comunales
$5 \mathrm{Ha}$.
$3 \mathrm{A.}$
$75 \mathrm{ca}$.

$\begin{array}{lllllllllllllll}\text { Superficie término municipal } & \ldots & \ldots & \ldots & \ldots & \ldots & \ldots & \ldots & \ldots & \ldots & \ldots & \ldots & \ldots & 2.399 \mathrm{Ha} .\end{array}$

$\begin{array}{lllllllllllllllllllllll}\text { Porcentaje } & \ldots & \ldots & \ldots & \ldots & \ldots & \ldots & \ldots & \ldots & \ldots & \ldots & \ldots & \ldots & \ldots & \ldots & \ldots & \ldots & \ldots & \ldots & \ldots & 0,02\end{array}$

28. MONTERRUBIO DE LA ARMUNA

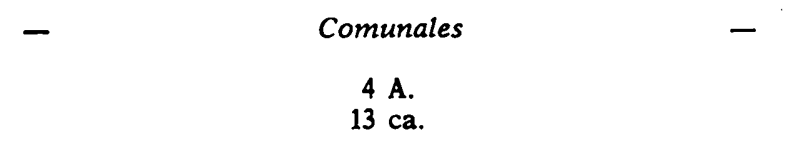

$\begin{array}{llllllllllllllll}\text { Superficie término municipal } & \ldots & \ldots & \ldots & \ldots & \ldots & \ldots & \ldots & \ldots & \ldots & \ldots & \ldots & \ldots & 1.120 \mathrm{Ha}\end{array}$

$\begin{array}{llllllllllllllllllllllll}\text { Porcentaje } & \ldots & \ldots & \ldots & \ldots & \ldots & \ldots & \ldots & \ldots & \ldots & \ldots & \ldots & \ldots & \ldots & \ldots & \ldots & \ldots & \ldots & \ldots & \ldots & 0,003\end{array}$

29. MORISCOS

$\begin{array}{ccc}\text { Propios } & \text { Comunales } & \text { Total } \\ 4 \mathrm{Ha} . & -\overline{\mathrm{A}} & 4 \mathrm{Ha} . \\ 87 \mathrm{A.} & 20 \mathrm{ca} . & 91 \mathrm{~A} . \\ 9 \mathrm{ca} . & 29 \mathrm{ca} .\end{array}$

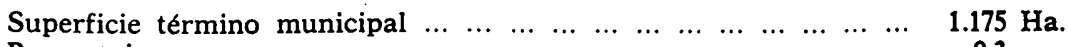

$\begin{array}{llllllllllllllllllllll}\text { Porcentaje } & \ldots & \ldots & \ldots & \ldots & \ldots & \ldots & \ldots & \ldots & \ldots & \ldots & \ldots & \ldots & \ldots & \ldots & \ldots & \ldots & \ldots & \ldots & \ldots & \ldots & 0,3\end{array}$ 
30. MOZARBEZ

$\begin{array}{ccc}\text { Propios } & \text { Comunales } & \text { Total } \\ 98 \mathrm{Ha} . & 185 \mathrm{Ha} . & 283 \mathrm{Ha} . \\ 7 \mathrm{~A} . & 32 \mathrm{~A} . & 40 \mathrm{~A} . \\ 49 \mathrm{ca} . & 65 \mathrm{ca} . & 14 \mathrm{ca} .\end{array}$

Superficie término municipal

31. MOZODIEL DE SACHINIGO

$$
\begin{aligned}
& \text { Propios } \\
& 13 \mathrm{Ha} . \\
& 8 \mathrm{~A} . \\
& 48 \mathrm{ca} .
\end{aligned}
$$

Superficie término municipal

Porcentaje

\section{PAJARES DE LA LAGUNA}

$$
\begin{aligned}
& \text { Comunales } \\
& \begin{array}{l}
37 \mathrm{Ha} . \\
53 \mathrm{~A} . \\
13 \mathrm{ca} .
\end{array}
\end{aligned}
$$

Superficie término municipal

33. PALENCIA DE NEGRILLA

$\begin{array}{ccc}\text { Propios } & \text { Comunales } & \text { Total } \\ 8 \mathrm{Ha} . & 5 \mathrm{Ha} . & 14 \mathrm{Ha} . \\ 94 \mathrm{~A} . & 26 \mathrm{~A} . & 21 \mathrm{~A} . \\ 94 \mathrm{ca} . & 89 \mathrm{ca} . & 83 \mathrm{ca} .\end{array}$

Superficie término municipal

34. PARADA DE ARRIBA

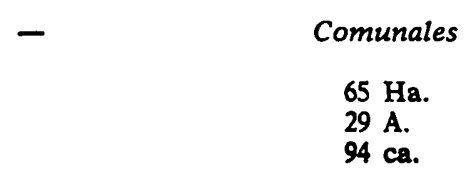

Superficie término municipal 
35. PARADA DE RUBIALES

$\begin{array}{ccr}\text { Propios } & \text { Comunales } & \text { Total } \\ & & \\ 326 \mathrm{Ha} . & 19 \mathrm{Ha} . & 346 \mathrm{Ha} . \\ 82 \mathrm{~A} . & 81 \mathrm{A.} & 63 \mathrm{~A} . \\ 14 \mathrm{ca} . & 70 \mathrm{ca} . & 84 \mathrm{ca} .\end{array}$

Superficie término municipal

$3.142 \mathrm{Ha}$.

Porcentaje

36. PEDROSILLO EL RALO

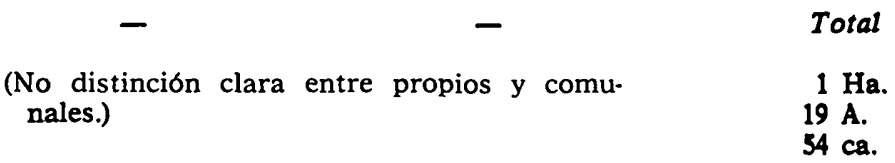

Superficie término municipal

$858 \mathrm{Ha}$.

Porcentaje

37. PELABRAVO

$\begin{array}{lcr}\text { Propios } & \text { Comunales } & \text { Total } \\ 51 \mathrm{Ha} . & 73 \mathrm{Ha} . & 124 \mathrm{Ha} . \\ 22 \mathrm{~A} . & 22 \mathrm{~A} . & 44 \mathrm{~A} . \\ 66 \mathrm{ca} . & 4 \mathrm{ca} . & 70 \mathrm{ca} .\end{array}$

Superficie término municipal $2.317 \mathrm{Ha}$.

Porcentaje

38. SAN CRISTOBAL DE LA CUESTA

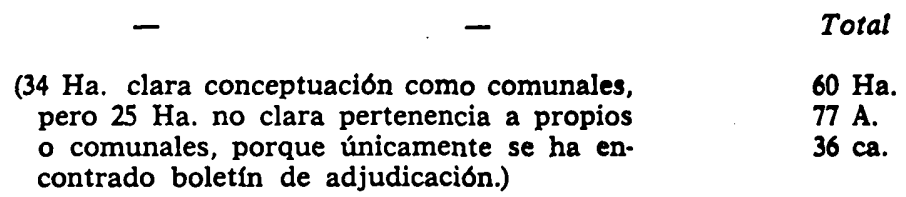

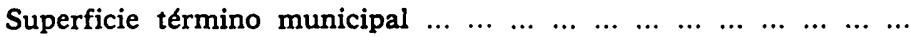

$\begin{array}{lllllllllllllllllllll}\text { Porcentaje } & \ldots & \ldots & \ldots & \ldots & \ldots & \ldots & \ldots & \ldots & \ldots & \ldots & \ldots & \ldots & \ldots & \ldots & \ldots & \ldots & \ldots & \ldots & \ldots\end{array}$

$995 \mathrm{Ha}$.

6

39. SAN PEDRO DE ROZADOS

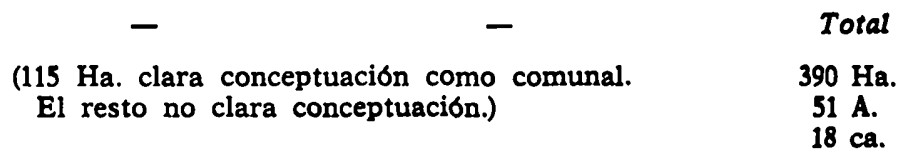

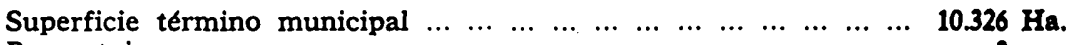

$\begin{array}{lllllllllllllllllllllll}\text { Porcentaje } & \ldots & \ldots & \ldots & \ldots & \ldots & \ldots & \ldots & \ldots & \ldots & \ldots & \ldots & \ldots & \ldots & \ldots & \ldots & \ldots & \ldots & \ldots & \ldots & & 3\end{array}$ 
40. SANTA MARTA DE TORMES

$\begin{array}{lcc}\text { Propios } & \text { Comunales } & \text { Total } \\ 17 \mathrm{Ha} . & - & 18 \mathrm{Ha} . \\ 97 \mathrm{A.} & 17 \mathrm{~A} . & 14 \mathrm{~A} . \\ 19 \mathrm{ca} . & 11 \mathrm{ca} . & 30 \mathrm{ca} .\end{array}$

(Llama la atención la gran división del terreno.)

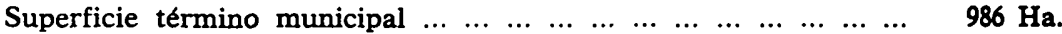

Porcentaje

41. TEJARES

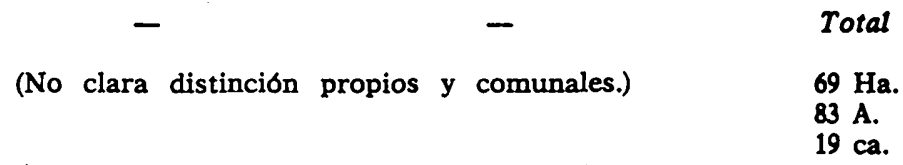

Superficie término municipal

$1.014 \mathrm{Ha}$. Porcentaje

42. TOPAS

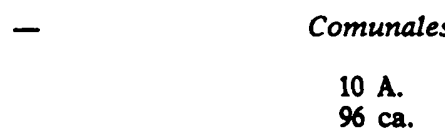

$\begin{array}{llllllllllllll}\text { Superficie término municipal } & \ldots & \ldots & \ldots & \ldots & \ldots & \ldots & \ldots & \ldots & \ldots & \ldots & \ldots & \ldots & 11.101 \mathrm{Ha}\end{array}$

$\begin{array}{lllllllllllllllllllllll}\text { Porcentaje } & \ldots & \ldots & \ldots & \ldots & \ldots & \ldots & \ldots & \ldots & \ldots & \ldots & \ldots & \ldots & \ldots & \ldots & \ldots & \ldots & \ldots & \ldots & \ldots & 0,0009\end{array}$

43. TORRESMENUDAS

$\begin{array}{lcr}\text { Propios } & \text { Comunales } & \text { Total } \\ & & \\ 47 \mathrm{Ha} . & 253 \mathrm{Ha} . & 301 \mathrm{Ha} . \\ 44 \mathrm{~A} . & 92 \mathrm{~A} . & 37 \mathrm{~A} . \\ 65 \mathrm{ca} . & 44 \mathrm{ca} . & 9 \mathrm{ca} .\end{array}$

$\begin{array}{llllllllllllll}\text { Superficie término municipal } & \ldots & \ldots & \ldots & \ldots & \ldots & \ldots & \ldots & \ldots & \ldots & \ldots & \ldots & \ldots & 1.180 \mathrm{Ha} .\end{array}$

Porcentaje

44. VALVERDON

$\begin{array}{ccc}- & \text { Comunales } & \text { Total } \\ \text { (Más vuelo monte alto } & 48 \mathrm{~A} . & 48 \mathrm{~A} . \\ \text { de encina) } & 74 \mathrm{ca} . & 74 \mathrm{ca} .\end{array}$

Superficie término municipal

2.215 Ha.

Porcentaje 
45. LAS VEGUILLAS

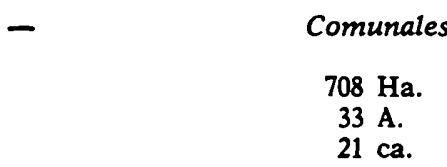

Superficie término municipal

$4.396 \mathrm{Ha}$.

Porcentaje

16

46. VILLAMAYOR

Comunales
$4 \mathrm{Ha}$.
$20 \mathrm{~A}$.
$23 \mathrm{ca}$.

$\begin{array}{lllllllllllllll}\text { Superficie término municipal } & \ldots & \ldots & \ldots & \ldots & \ldots & \ldots & \ldots & \ldots & \ldots & \ldots & \ldots & \ldots & 3.947 \mathrm{Ha} .\end{array}$

$\begin{array}{lllllllllllllllllllllll}\text { Porcentaje } & \ldots & \ldots & \ldots & \ldots & \ldots & \ldots & \ldots & \ldots & \ldots & \ldots & \ldots & \ldots & \ldots & \ldots & \ldots & \ldots & \ldots & \ldots & \ldots & 0,10\end{array}$

47. VILLARES DE LA REINA

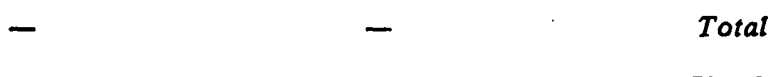

$170 \mathrm{~m}^{2}$

$\begin{array}{llllllllllllll}\text { Superficie término municipal } & \ldots & \ldots & \ldots & \ldots & \ldots & \ldots & \ldots & \ldots & \ldots & \ldots & \ldots & \ldots & 2.155 \\ \text { Ha }\end{array}$

$\begin{array}{lllllllllllllllllllllll}\text { Porcentaje } & \ldots & \ldots & \ldots & \ldots & \ldots & \ldots & \ldots & \ldots & \ldots & \ldots & \ldots & \ldots & \ldots & \ldots & \ldots & \ldots & \ldots & \ldots & \ldots & 0,007\end{array}$

48. VILLAVERDE DE LA GUARENA

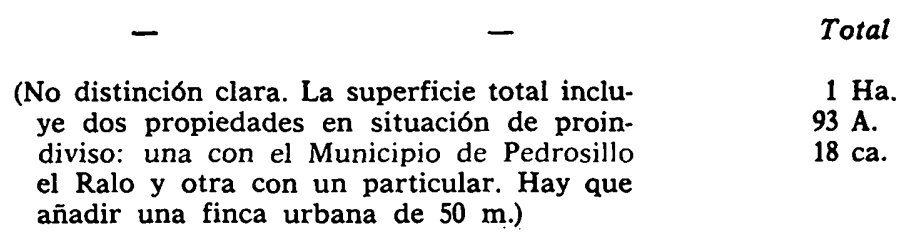

$\begin{array}{llllllllllllll}\text { Superficie término municipal } & \ldots & \ldots & \ldots & \ldots & \ldots & \ldots & \ldots & \ldots & \ldots & \ldots & \ldots & \ldots & 1.636 \mathrm{Ha}\end{array}$

$\begin{array}{llllllllllllllllllllll}\text { Porcentaje } & \ldots & \ldots & \ldots & \ldots & \ldots & \ldots & \ldots & \ldots & \ldots & \ldots & \ldots & \ldots & \ldots & \ldots & \ldots & \ldots & \ldots & \ldots & \ldots & 0,11\end{array}$

49. SALAMANCA
Propios (rústica) Propios urbanos
$735 \mathrm{Ha}$. $\quad 5.159,55 \mathrm{~m}^{2}+$ proindiviso en Plaza de Toros:
$18 \mathrm{~A}$.
5 partes de 93

$\begin{array}{llllllllllllll}\text { Superficie término municipal } & \ldots & \ldots & \ldots & \ldots & \ldots & \ldots & \ldots & \ldots & \ldots & \ldots & \ldots & \ldots & 3.962 \mathrm{Ha}\end{array}$

$\begin{array}{llllllllllllllllllll} & \text { Porcentaje } \\ \ldots & \ldots & \ldots & \ldots & \ldots & \ldots & \ldots & \ldots & \ldots & \ldots & \ldots & \ldots & \ldots & \ldots & \ldots & \ldots & \ldots & \ldots & \ldots & \ldots \\ \end{array}$ 


\section{APÉNDICE NÚMERO 4}

Estimación actual de las propiedades de los Municipios del Partido judicial de Salamanca (muestra).

\section{RELACION DE MUNICIPIOS CON EXPRESION DE SUS BIENES A 31 DE AGOSTO DE 1977 *}

\section{a) Municipios que fueron objeto de desamortización}

\section{Aldeatejada.}

No posee bienes comunales.

No posee bienes de propios.

\section{Arcediano.}

Bienes comunales: constituidos por $25 \mathrm{Ha}$., integradas por cinco prados y dos alamedas.

Bienes de propios: $55 \mathrm{Ha}$. procedentes de la masa común de la concentración parcelaria.

\section{Barbadillo.}

No posee bienes comunales.

Bienes de propios: integrados por $3 \mathrm{Ha}$. de diversas superficies propiedad municipal existentes junto al pueblo, $7 \mathrm{Ha}$. dedicadas al cultivo de cereales, $17 \mathrm{Ha}$. dedicadas a huertos familiares y $40 \mathrm{Ha}$. dedicadas a prados y pastos. Suman, en total, $67 \mathrm{Ha}$.

\section{Calzada de Don Diego.}

No posee bienes comunales.

Bienes de propios: $2 \mathrm{Ha}$. dedicadas a cultivo de cereales y $2 \mathrm{Ha}$ y $33 \mathrm{~A}$. dedicadas a pastizal. Suman, en total, $4 \mathrm{Ha}$. y $33 \mathrm{~A}$.

\section{Calzada de Valdunciel.}

Bienes comunales: $240 \mathrm{Ha}$. y $55 \mathrm{~A}$., destinadas a cultivo agrícola.

Bienes de propios: $63 \mathrm{Ha}$. y $71 \mathrm{~A}$., dedicadas a pastizales. (No ha sido posible concretar si las superficies mencionadas integran una unidad o están formadas por la integración de varias superficies).

\section{Castellanos de Moriscos.}

No posee bienes comunales.

Bienes de propios: $4 \mathrm{Ha}$. y $83 \mathrm{~A}$., integradas por varias unidades diseminadas. La superficie de bienes de propios puede ser incrementada con base en la masa común de concentración parcelaria.

* Todos estos datos han sido facilitados por los Secretarios municipales. Hubiera sido nuestro deseo evitar muestras y operar sobre los datos relativos a la totalidad de los Municipios del Partido judicial, pero lo ha impedido una injustificada desatención a los inventarios de bienes, que contrasta con el claro tenor literal del artículo 200 de la Ley de Régimen local y con el aún más explícito tenor literal de los artículos 16-34 del Reglamento de Bienes de las Corporaciones locales. 


\section{7.' Calvarrasa de Abajo.}

No posee bienes comunales.

Bienes de propios: tres parcelas de regadío de 9 A. y 66 ca., 82 A. y 15 ca. y $6 \mathrm{Ha}$ y $95 \mathrm{~A}$., y dos parcelas de secano de $1 \mathrm{Ha}$ y $15 \mathrm{~A}$. y $2 \mathrm{Ha}$ y $35 \mathrm{~A}$.

\section{Carrascal del Obispo.}

No posee bienes comunales.

Bienes de propios: $109 \mathrm{Ha}$. de pastos con monte de encina.

\section{Cilleros el Hondo.}

No posee bienes comunales.

No posee bienes de propios.

\section{Doñinos de Salamanca.}

No posee bienes comunales.

Bienes de propios: $22 \mathrm{Ha}$. y $86 \mathrm{~A}$., integradas por varias unidades superficiales.

11. Encinas de Abajo.

No posee bienes comunales.

Bienes de propios: tres parcelas de 10 A., 46 A. y 88 A., y tres superficies de $2 \mathrm{Ha}$ y 53 A., $3 \mathrm{Ha}$ y 75 ca. y $7 \mathrm{Ha}$ y $96 \mathrm{~A}$.

\section{Espino de la Orbada.}

No posee bienes comunales.

Bienes de propios: 12 parcelas que suman, en total, $145 \mathrm{Ha}$., dedicadas a pasto, de las cuales $13 \mathrm{Ha}$. se dedican a huertos familiares.

Un total de 24 parcelas que suman $54 \mathrm{Ha}$., todas de cereal de secano y explotadas por vecinos de la localidad con cinco años de residencia.

13. Florida de Liébana.

No posee bienes comunales.

No posee bienes de propios.

14. Forfoleda.

No posee bienes comunales.

Bienes de propios: $12 \mathrm{Ha}$. y $17 \mathrm{~A}$., integradas por varias parcelas dedicadas a pastos y huertos familiares.

\section{Galindo y Perahuy.}

No posee bienes comunales.

No posee bienes de propios.

16. Mozárbez.

No posee bienes comunales.

Bienes de propios: 3 Ha. y 8 A., integradas por varias parcelas.

\section{Pàrada de Arriba.}

No posee bienes comunales.

Bienes de propios: 2 Ha. y 21 A. 
18. Pelabravo.

No posee bienes comunales.

Bienes de propios: 10 parcelas que no llegan a $1 \mathrm{Ha}$. de superficie individual, tres parcelas que superan la superficie individual de $1 \mathrm{Ha}$., una parcela de $2 \mathrm{Ha}$., una parcela de $3 \mathrm{Ha}$. y una finca de $10 \mathrm{Ha}$.

19. Pino de Tormes.

Bienes comunales: $1 \mathrm{Ha}$. y $59 \mathrm{~A}$., dedicadas a pasto.

Bienes de propios: 10 parcelas que suman $3 \mathrm{Ha}$. de regadío, una parcela de $2 \mathrm{Ha}$. de secano y una superficie forestal de $44 \mathrm{~A}$.

20. San Pedro de Rozados.

No posee bienes comunales.

Bienes de propios: un total de $33 \mathrm{Ha}$., dedicadas a pastos y a 83 huertos familiares de $11 \mathrm{~A}$. cada uno.

21. Santa Marta de Tormes.

No posee bienes comunales.

No posee bienes de propios.

22. Villamayor.

Califica como comunales 6 Ha. y 55 A., de pastos, que se arriendan, 9 Ha. y $28 \mathrm{~A}$. de huertos familiares y tres pequeñas parcelas improductivas.

Califica como de propios 1 Ha. y 8 A., dedicadas a pastos, y 1 Ha. y 94 A., improductivas.

23. Villares de la Reina.

No posee bienes comunales.

Bienes de propios: dos pequeñas parcelas que no superan conjuntamente $1 \mathrm{Ha}$.

b) Ayuntamientos no afectados por la desamortización

1. Carbajosa de la Sagrada.

Carece de bienes comunales y de propios.

2. Cabezabellosa.

Carece de bienes comunales y de propios.

3. Pitiegua.

Carece de bienes comunales y de propios.

4. Robliza de Cojos.

Carece de bienes comunales y de propios.

5. Tardáguila.

No califica ningún bien como comunal.

Califica como de propios: 59 fincas, que suman $250 \mathrm{Ha}$; cinco prados, que suman $71 \mathrm{Ha}$; dos montes de $15 \mathrm{Ha}$. y $80 \mathrm{Ha}$.; de los cinco prados, cuatro son dedicados a aprovechamiento por los vecinos.

6. Villalba de los Llanos.

Carece de bienes comunales y de propios. 


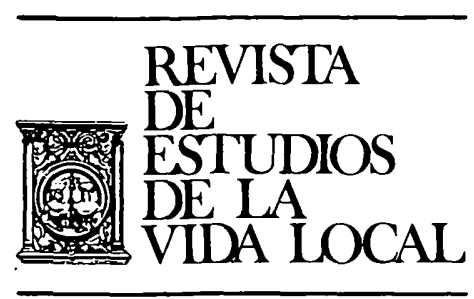

\section{CRONICAS}


REVL-1978, núm. 197. SANCHEZ BLANCO, ANGEL. INCIDENCIAS DE LA LEGISLACION DESAMO... REVL-1978, núm. 197. SANCHEZ BLANCO, ANGEL. INCIDENCIAS DE LA LEGISLACION DESAMO... 